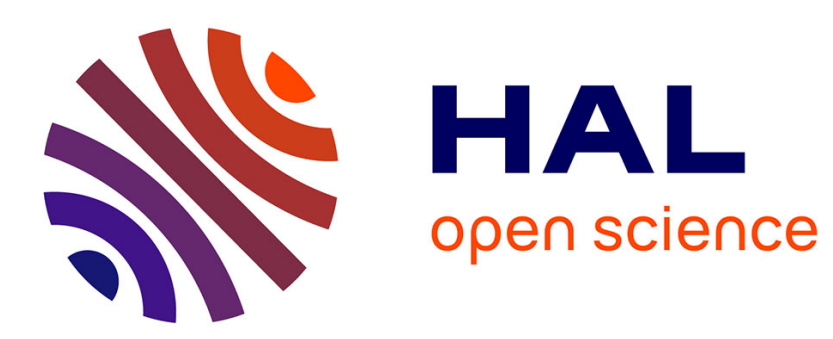

\title{
Development of Characterization Techniques of Thermodynamic and Physical Properties Applied to the CO2-DMSO Mixture
}

Brice Calvignac, Élisabeth Rodier, Jean-jacques Letourneau, Jacques Fages

\section{- To cite this version:}

Brice Calvignac, Élisabeth Rodier, Jean-jacques Letourneau, Jacques Fages. Development of Characterization Techniques of Thermodynamic and Physical Properties Applied to the CO2-DMSO Mixture. International Journal of Chemical Reactor Engineering, 2009, 7 (1), pp.A46. 10.2202/15426580.2095. hal-01142135

\section{HAL Id: hal-01142135 \\ https://imt-mines-albi.hal.science/hal-01142135}

Submitted on 14 Apr 2015

HAL is a multi-disciplinary open access archive for the deposit and dissemination of scientific research documents, whether they are published or not. The documents may come from teaching and research institutions in France or abroad, or from public or private research centers.
L'archive ouverte pluridisciplinaire HAL, est destinée au dépôt et à la diffusion de documents scientifiques de niveau recherche, publiés ou non, émanant des établissements d'enseignement et de recherche français ou étrangers, des laboratoires publics ou privés. 


\title{
INTERNATIONAL JOURNAL OF CHEMICAL REACTOR ENGINEERING
}

\section{Development of Characterization Techniques of Thermodynamic and Physical Properties Applied to the $\mathrm{CO}_{2}$-DMSO Mixture}

\author{
Brice Calvignac* \\ Elisabeth Rodier ${ }^{\dagger}$ \\ Jean-Jacques Letourneau ${ }^{\ddagger}$ \\ Jacques Fages**
}

*Université de Toulouse, brice.calvignac@mines-albi.fr

†Université de Toulouse, elisabeth.rodier@mines-albi.fr

${ }^{\ddagger}$ Université de Toulouse, letourne@mines-albi.fr

**Université de Toulouse, jacques.fages@mines.albi.fr ISSN 1542-6580 


\title{
Development of Characterization Techniques of Thermodynamic and Physical Properties Applied to the $\mathrm{CO}_{2}$-DMSO Mixture*
}

Brice Calvignac, Elisabeth Rodier, Jean-Jacques Letourneau, and Jacques Fages

\begin{abstract}
This work is focused on the development of new characterization techniques of physical and thermodynamic properties. These techniques have been validated using the binary system DMSO- $\mathrm{CO}_{2}$ for which several studies of characterization have been well documented. We focused on the DMSO-rich phase and we carried out measurements of volumetric expansion, density, viscosity and $\mathrm{CO}_{2}$ solubility at $298.15,308.15$ and $313.15 \mathrm{~K}$ and pressures up to $9 \mathrm{MPa}$. The experimental procedures were compared and validated with the available literature data on $\mathrm{SC}-\mathrm{CO}_{2}$-DMSO system. We made density and $\mathrm{CO}_{2}$ solubility measurements, using respectively the vibrating tube technology and two static analytical methods. Lastly, we developed an innovative falling body viscosimeter for high pressure measurements. All the measurements made are in good agreement with the already published data in spite of very different experimental techniques. This work is a contribution to the understanding of the DMSO- $\mathrm{CO}_{2}$ binary as it implements new viscosity data. Moreover, it opens new perspectives about the determination of the properties of other systems such as polymers- $\mathrm{CO}_{2}$ and fats- $\mathrm{CO}_{2}$, which are essential for supercritical process design such as extraction, crystallization, chromatography and synthesis reaction.
\end{abstract}

KEYWORDS: thermophysical properties, phase equilibrium, density, viscosity, DMSO, supercritical $\mathrm{CO}_{2}$

\footnotetext{
*The authors are affiliated with the Université de Toulouse, Ecole des Mines d'Albi-Carmaux, Centre RAPSODEE FRE-CNRS 3213. The authors would like to acknowledge the financial support of CNRS (France) and the Carnot Institute M.I.N.E.S. (France).
} 


\section{Erratum}

The original citation for this article published on October 27th 2009 was as follows:

Calvignac, Brice; Elisabeth, Rodier; Jean-Jacques, Letourneau; and Jacques, Fages (2009) "Development of Characterization Techniques of Thermodynamic and Physical Properties Applied to the CO2-DMSO Mixture," International Journal of Chemical Reactor Engineering: Vol. 7: A46.

The citation was corrected on February 23rd 2010 as follows:

Calvignac, Brice; Rodier, Elisabeth; Letourneau, Jean-Jacques; and Fages, Jacques (2009) 'Development of Characterization Techniques of Thermodynamic and Physical Properties Applied to the CO2-DMSO Mixture," International Journal of Chemical Reactor Engineering: Vol. 7: A46. 


\section{Introduction}

Supercritical fluid (SCF) processes are technologies used as clean and efficient alternatives to conventional methods in several fields such as extraction, crystallization, chromatography, material processing (Bertucco et al., 2001). Carbon dioxide $\left(\mathrm{CO}_{2}\right)$ is the most commonly SCF used and is a solvent of choice because of its non-toxicity and its moderate critical properties (critical pressure: $7.38 \mathrm{MPa}$, critical temperature: $304.35 \mathrm{~K}$ ). Dimethyl sulfoxide (DMSO) is a powerful organic solvent, able to dissolve many products such as proteins, polysaccharides, biodegradable polymers, and pharmaceutical compounds. Nowadays, pharmaceutical industries are struggling with the increasing problem of the lack of bioavailability of candidate drug molecules. Supercritical particle generation processes such as Supercritical Anti-Solvent (SAS) processes (Fages et al., 2004; Rodier et al., 2005; Majerik et al., 2007; Su et al., 2009; Cocero et al., 2009; Calvignac et al., 2009c) can help solving this problem. Indeed, they can lead to micronization, and depending on operating conditions, they can allow the control of particle size, particle size distribution, particle shape and crystal polymorphism. Both the $\mathrm{SC}-\mathrm{CO}_{2}$ and the organic solvent containing a solute, are injected through a nozzle into a continuum of $\mathrm{SC}-\mathrm{CO}_{2}$, the latter playing the role of an anti-solvent. Due to the bidirectional mass transfer between the $\mathrm{SC}-\mathrm{CO}_{2}$ and the organic solution, supersaturation in the micronized "droplets" is reached leading then to the solute precipitation. One of the main important remaining drawbacks is the presence of residual solvent in the particles. So, in order to control such processes, the knowledge of Vapour-Liquid Equilibrium (VLE) and physical properties of binary mixtures solvent/antisolvent and ternary mixtures including the solute, are essential over an extended range of temperatures and pressures. All studies on the binary mixture $\mathrm{CO}_{2}$-DMSO are reported in Table 1 . Other investigations were carried out on ternaries mixtures $\mathrm{CO}_{2}-\mathrm{DMSO}-\mathrm{H}_{2} \mathrm{O}$ (Andreatta et al., 2007; Perez de Diego et al., 2005) and $\mathrm{CO}_{2}$-DMSO-dextran (Perez de Diego et al., 2005). Considering this rather well documented literature and because it is one of the most used, we have chosen the $\mathrm{SC}-\mathrm{CO}_{2}$-DMSO binary mixture in order to validate the new experimental set-up and to implement new values concerning density and viscosity. In addition, this binary is one of the most adequate for the different techniques investigated, as its properties are suitable with the operating ranges considered. In this work, characterization of physical properties such as density and viscosity, and phase equilibrium properties, as $\mathrm{CO}_{2}$ solubility and volumetric expansion, were achieved on $\mathrm{DMSO}-\mathrm{CO}_{2}$ over a range of temperatures between 298 and $318 \mathrm{~K}$ and at pressures up to $9 \mathrm{MPa}$. 
Table 1. Summary of the studies on $\mathrm{CO}_{2}$-DMSO system

\begin{tabular}{|c|c|c|c|c|}
\hline System & $\boldsymbol{T}(\mathbf{K})$ & $\boldsymbol{P}$ (MPa) & Studied properties & Reference \\
\hline \multirow{5}{*}{ CO $_{2}$-DMSO } & 298,303 & $0.2-6.6$ & $\begin{array}{c}\text { Volumetric Expansion, } \\
\text { VLE, Density }\end{array}$ & $\begin{array}{c}\text { Kordikowski } \text { et al. } \\
\text { (1995) }\end{array}$ \\
\cline { 2 - 5 } & $\begin{array}{c}309,314, \\
321,328\end{array}$ & $4-12.6$ & VLE & $\begin{array}{c}\text { Vega Gonzalez } \text { et al. } \\
(2002)\end{array}$ \\
\cline { 2 - 5 } & $\begin{array}{c}298,308, \\
318\end{array}$ & $1-9$ & $\begin{array}{c}\text { Volumetric expansion, } \\
\text { VLE }\end{array}$ & $\begin{array}{c}\text { Rajasingam } \text { et al. } \\
(2004)\end{array}$ \\
\cline { 2 - 6 } & 280 to 370 & $0.5-13$ & VLE & Andreatta et al. (2007) \\
\cline { 2 - 5 } & $\begin{array}{c}313,329, \\
338,348\end{array}$ & $4-14$ & VLE & Chiu et al. (2008) \\
\cline { 2 - 6 } & $\begin{array}{c}298,308, \\
318\end{array}$ & $1-9$ & $\begin{array}{c}\text { Volumetric expansion, } \\
\text { VLE, Density, Viscosity }\end{array}$ & This work \\
\hline
\end{tabular}

\section{Material and Methods}

\subsection{Materials}

DMSO (Purity $99 \%$ ) was obtained from Fluka (Buchs, Switzerland). Because of its hygroscopicity, a drying step under vacuum was necessary before each experiment during one hour. Carbon dioxide (purity $99.995 \%$ ) was purchased from Air liquide S.A. (Paris, France).

\subsection{Experimental set-up and procedures}

\subsubsection{Volumetric expansion measurements}

A schematic diagram of the experimental device for volumetric expansion measurements is shown in Figure 1. The apparatus (Sitec, Switzerland) has been designed to perform experiments at pressures and temperatures up to, respectively, $50 \mathrm{MPa}$ and $473.15 \mathrm{~K}$. The cell measurement was equipped with a heating jacket and two opposite sapphire windows: one for lighting and the other for the visualization of the volumetric expansion using a digital camera. The stainless steel cell was a vertical hollow cylinder with a total volume of $93.89 \pm 0.10 \mathrm{ml}$ (including pipes). The pressure in the apparatus was kept constant within $\pm 0.1 \mathrm{MPa}$. The cell temperature was controlled precisely $( \pm 0.2 \mathrm{~K})$ with a thermostated bath by means of a PT100 temperature probe. In addition, a magnetic stirrer homogenized the mixture until the thermodynamic equilibrium was reached, that was at least $30 \mathrm{~min}$ after no more variation of the pressure at 
constant temperature. The volumetric expansion measurement consisted in observing and recording the evolution of the liquid phase volume with pressure. This volume was calibrated as a function of the height of liquid, using DMSO at atmospheric pressure.

Calibration was done by determining the level of liquid from captured images for several known volumes of DMSO introduced in the cell by means of a syringe pump (Model ISCO 260D) with an accuracy of $\pm 0.01 \mathrm{ml}$. The hold-up volume $(2.04 \pm 0.01 \mathrm{ml})$ of the pipe between the cell and the syringe pump was taken into account for each injection. The level of the liquid $(H)$ was obtained by the analysis of the captured images with the ImageJ software (National Institute of Health, USA) and then correlated to the volume with a correlation coefficient of 0.9998. Note that the measurement of the height of liquid was estimated to be accurate within \pm 2 pixels.

As for the determination of the volumetric expansion (E) of the liquid phase, an initial volume $\left(\mathrm{V}_{0}\right)$ of DMSO was introduced into the cell at given temperature $(\mathrm{T})$ and atmospheric pressure $\left(\mathrm{P}_{0}\right)$ by the syringe pump. Then, $\mathrm{CO}_{2}$ was introduced at the same temperature $(\mathrm{T})$ and pressure $(\mathrm{P})$ by the piston pump. The mixture was homogenised until all experimental parameters were stabilised ( $\mathrm{T}, \mathrm{P}$ and $\mathrm{E}$ ) meaning that the thermodynamic equilibrium was reached. Besides, the volumetric expansion of the liquid phase at $(\mathrm{T})$ and $(\mathrm{P})$ was defined by:

$E(\%)=\frac{V(T, P)-V_{0}\left(T, P_{0}\right)}{V_{0}\left(T, P_{0}\right)} \cdot 100$ 


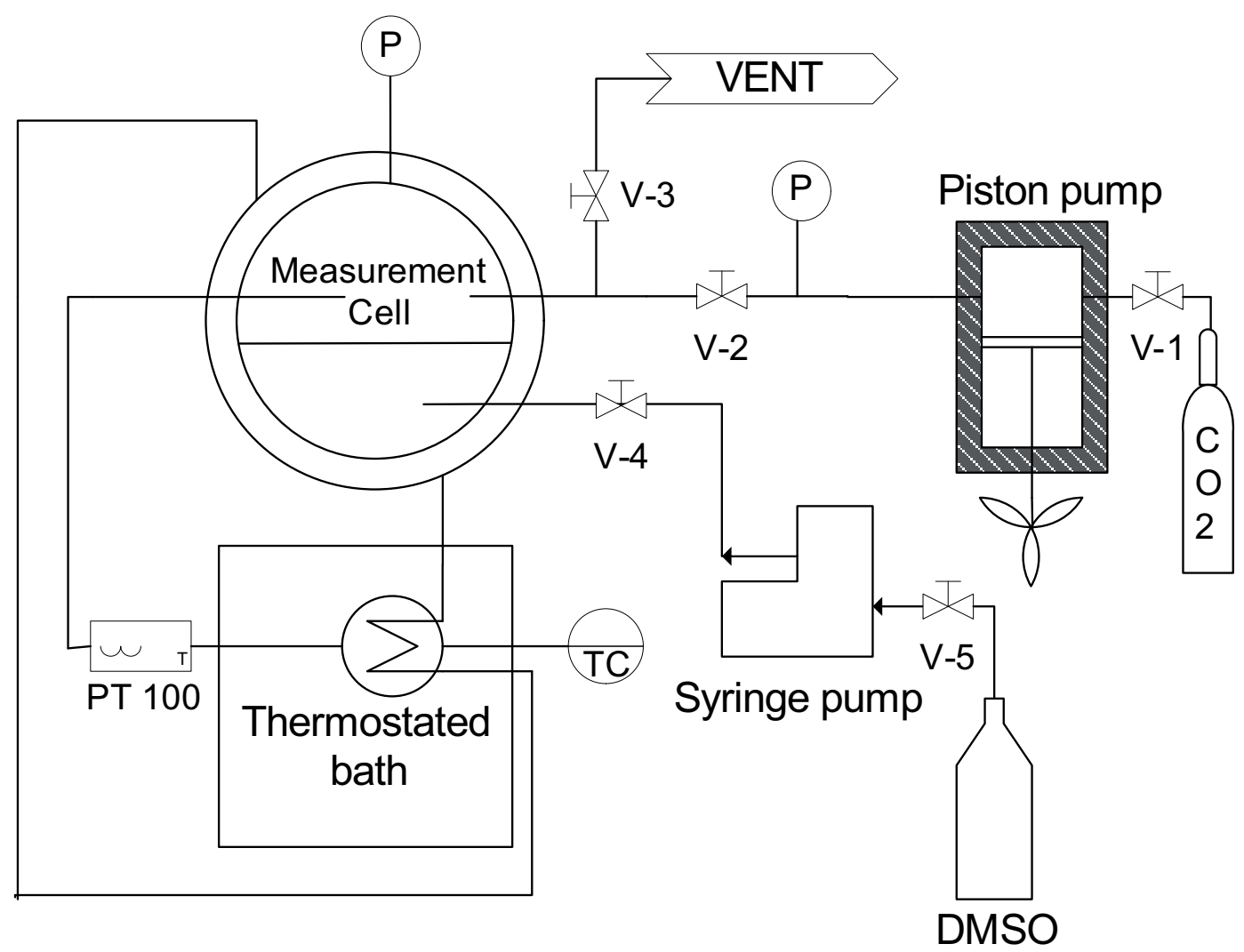

Figure 1. Schematic diagram of apparatus for volumetric expansion measurements

\subsubsection{Solubility measurements}

Schematic diagrams of the static analytical devices for solubility measurements are shown in Figure 2 and 3.

The first apparatus (Figure 2) has been designed to perform experiments at pressures and temperatures up to, respectively, $35 \mathrm{MPa}$ and $473.15 \mathrm{~K}$. A similar experimental set-up was previously used for characterization of melted cocoa butter saturated with supercritical $\mathrm{CO}_{2}$ (Calvignac et al., 2009a) for density measurements. The stainless steel autoclave (1) of $500 \mathrm{ml}$ capacity (Xenard, France) was previously loaded with a known volume of DMSO taking into account the volumetric expansion when introducing $\mathrm{CO}_{2}$. Liquid $\mathrm{CO}_{2}$ was pumped by a high pressure membrane pump (Lewa, France) (2) and preheated by a heat exchanger (Separex, France) (3) before filling the autoclave equipped with a stirring mechanical device (Top-industrie, France). The pressure (P) and temperature (T) of the VLE device were kept constant respectively within \pm 0.1 
$\mathrm{MPa}$ and $\pm 0.1 \mathrm{~K}$. Note the presence of a buffer storage tank (4) connected between the $\mathrm{CO}_{2}$ feed pipe and the autoclave. Once the equilibrium was reached, pressure in the tank was increased up to $1 \mathrm{MPa}$ above the equilibrium pressure in order to ensure pressure drop compensation when valves V-6 and V-7 were opened to make gravimetric analysis. Then, the pressure compensation operation was achieved by the membrane pump. The $\mathrm{CO}_{2}$ flow compensation was fixed to $1.5 \mathrm{~kg} \cdot \mathrm{h}^{-1}$ in order to minimize the pressure drop $\left(\mathrm{P}_{\max }=0.5 \mathrm{MPa}\right)$ manually controlled by V-2. Cell temperature was kept constant by a thermostatic bath within $\pm 0.1 \mathrm{~K}$. The measurement cell (5) was a stainless steel tube previously weighed empty with a balance (Sartorius Model LA3200B) having a wide weighing range (up to $6 \mathrm{~kg}$ ) and a good precision $( \pm 0.01 \mathrm{~g}$ ). It was used to sample the liquid phase. Volume of the sampling loop was small; consequently, equilibrium was hardly perturbed and reached again quickly. It is important to note that pipes and valves of the loop were thermally controlled within $\pm 0.1 \mathrm{~K}$. Once $\mathrm{P}$ and $\mathrm{T}$ were stable, they were recorded and valves V-6 and V-7 were closed to isolate the cell. Then, the cell was placed in an ice bath, in order to separate both compounds into gaseous $\mathrm{CO}_{2}$ and solid DMSO. Note that DMSO is solid below $291.6 \mathrm{~K}$ at atmospheric pressure. This operation consisted in slowly opening V-7 and avoiding losses of DMSO when degassing $\mathrm{CO}_{2}$. For it, the valve $\mathrm{V}-7$ was slowly opened and the mixture was degassed in order to recover DMSO and hence to deduce the solubility of $\mathrm{CO}_{2}$ in the liquid phase. Finally, after each experiment, the gravimetric analysis device was cleaned. 


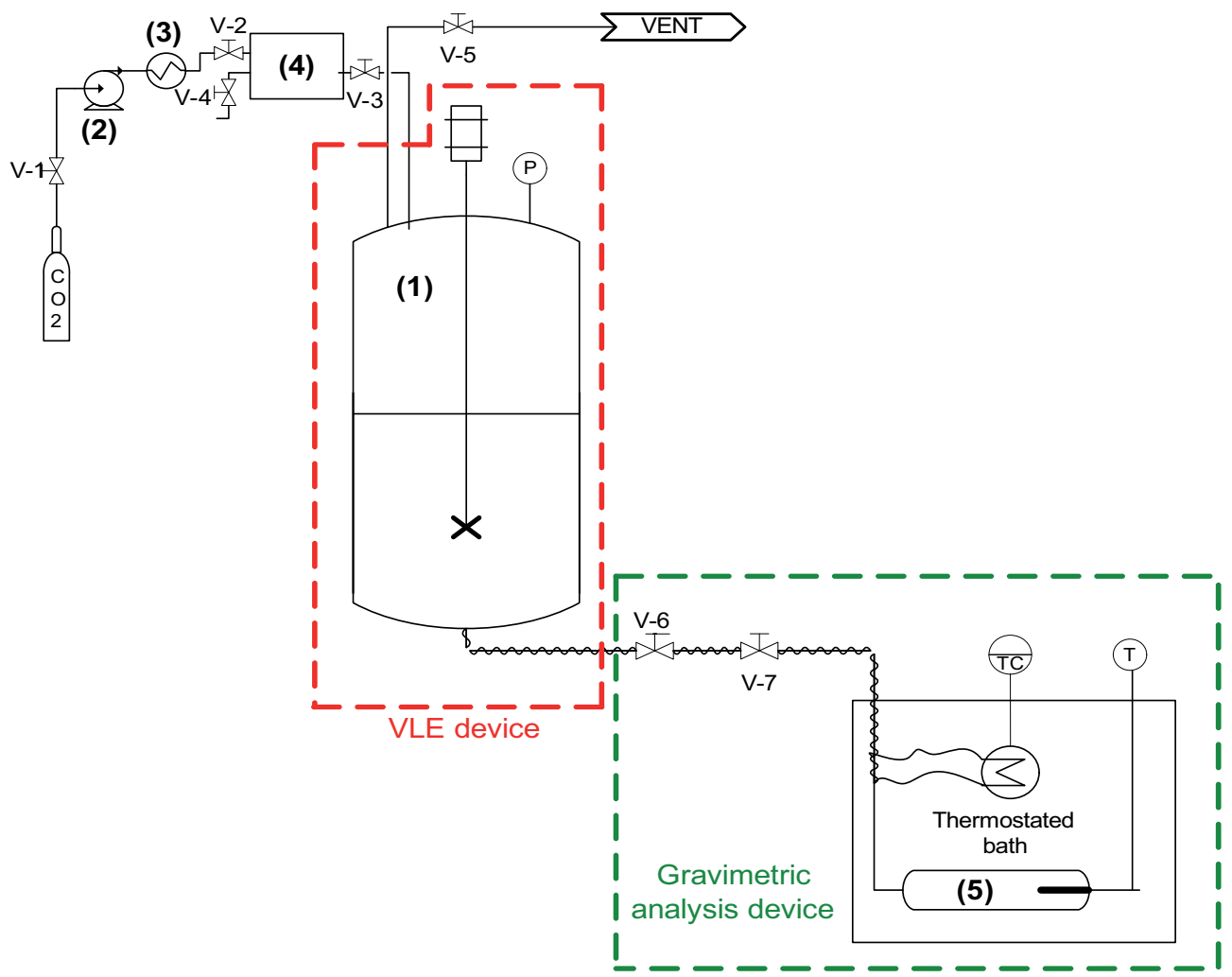

Figure 2. Schematic diagram of the solubility measurements device (device 1)

The second apparatus (Figure 3) has been designed to carry out investigations under the same operating conditions. The measurement method was the same as described previously. However, this original device was used as a variable volume cell with a removable part. The stainless steel tube (1) $(10 \mathrm{ml})$ was previously loaded with a known volume of liquid DMSO taking into account the final volume after volumetric expansion, which was previously measured. This tube contained two stainless steel balls, which were moved up and down periodically with magnets placed on the outside wall of the tube. This stirring device ensured a good homogenisation. $\mathrm{CO}_{2}$ was introduced into the expansion vessel (2) at the desired temperature (T) and pressure (P) by the syringe pump (ISCO Model 260D). Temperature of the pump was controlled by a thermostated bath within $\pm 0.01 \mathrm{~K}$. The expansion vessel (2) was a stainless steel tube whose volume was 5 times greater than the cell one (1). The stirring device and the use of a syringe pump with constant pressure control permitted to reach the thermodynamic equilibrium within 2 hours. In addition, this apparatus had the advantage to be well thermally controlled $( \pm 0.1 \mathrm{~K}$ ) because of its total immersion into the thermostatic bath. Once experimental parameters, pressure, temperature 
and compensation flow of the syringe pump were stable, they were recorded and the ball valve V-4 was closed to isolate the cell. The end of the procedure was the same as in the previous method. The cell (1) was disconnected and placed in an ice bath in order to separate $\mathrm{CO}_{2}$ from DSMO.

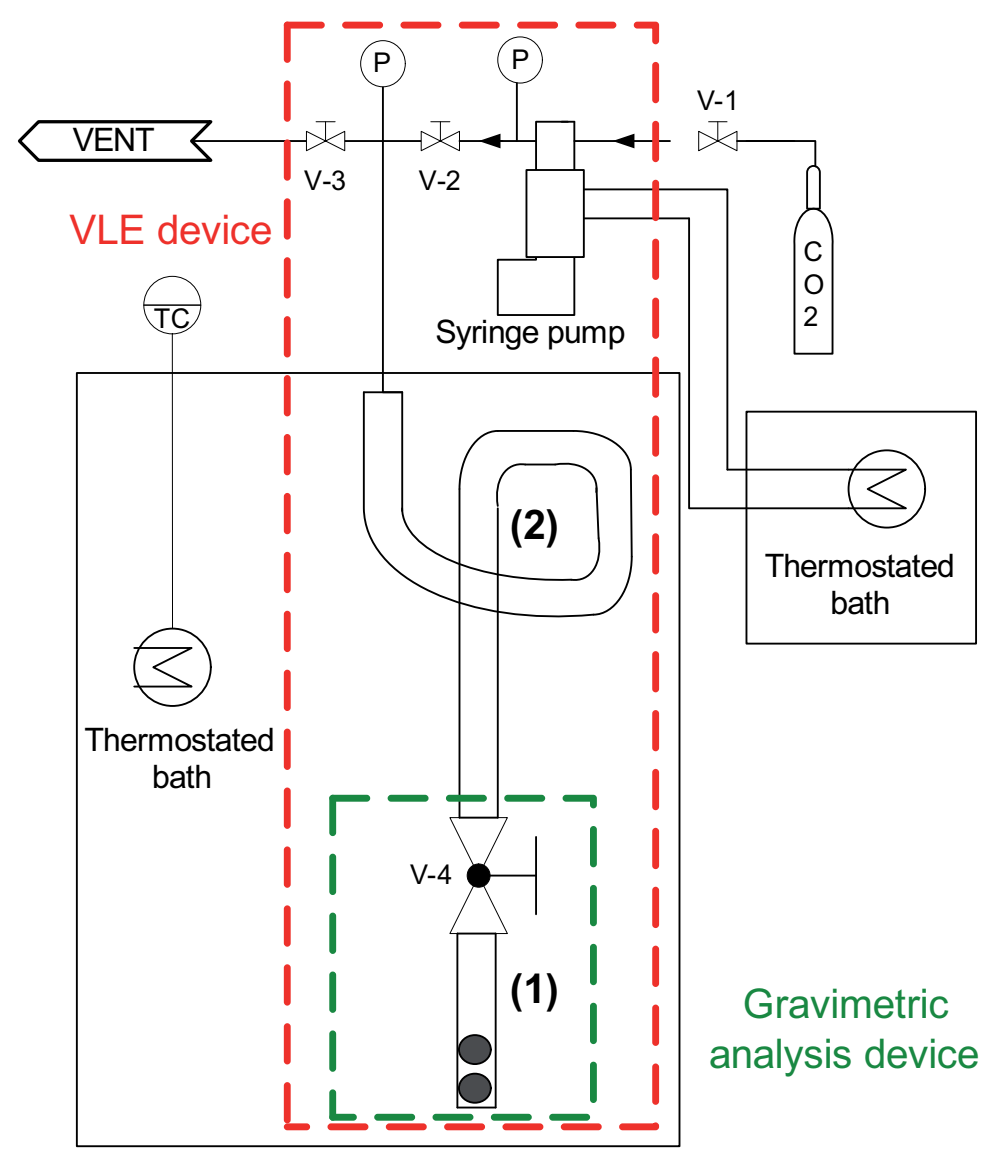

Figure 3. Schematic diagram of the solubility measurements device (device 2)

The main difference between both devices is the following. The device 1 needs a sampling and the gravimetric measurement is performed on the sample whereas in device 2, in situ measurement can be made. Hence, device 1 implies a mass transport of the liquid saturated phase, which might disturb the mixture.

In this work, the solubility of $\mathrm{CO}_{2}$ was defined as the mass percentage of $\mathrm{CO}_{2}\left(x_{\mathrm{CO} 2}\right)$ contained in the liquid phase rich in DMSO, according to: 


$$
X_{C O 2}(\%)=\frac{m_{\text {mixture }}-m_{D M S O}}{m_{\text {mixture }}} \cdot 100
$$

\subsubsection{Density measurements}

A schematic diagram of the experimental device for density measurements is shown in Figure 4.

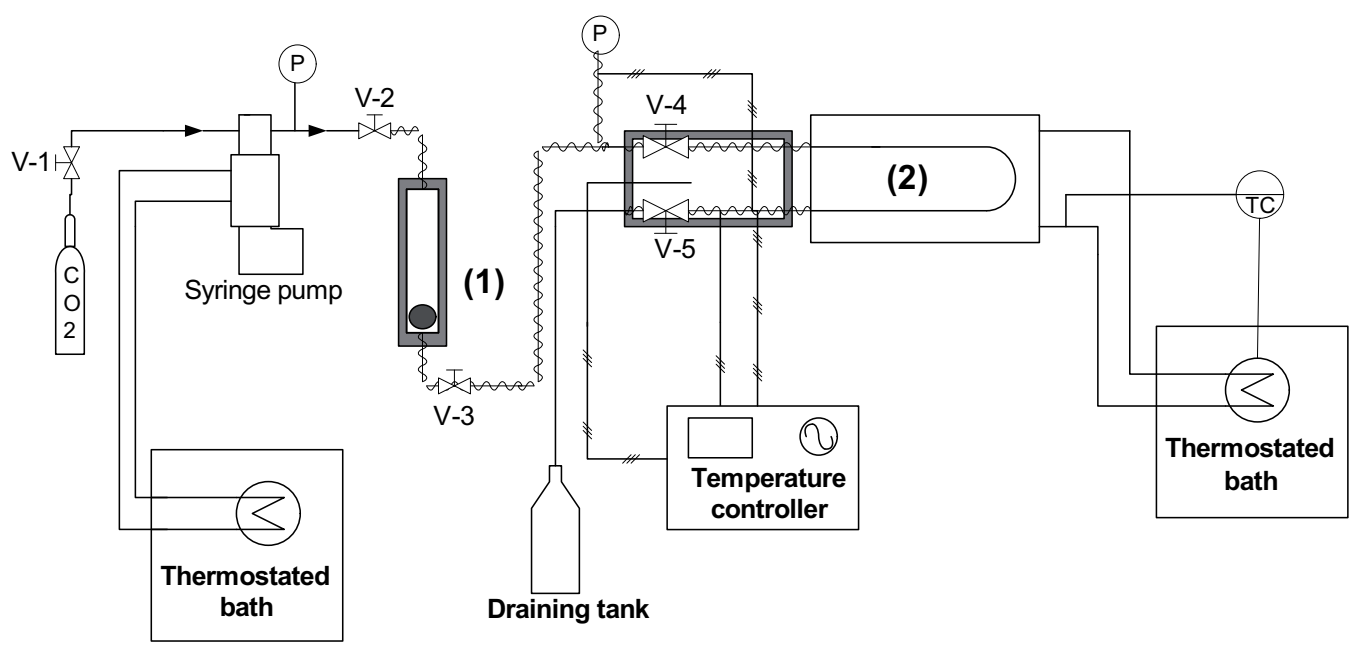

Figure 4. Schematic diagram of the apparatus for density measurements

The apparatus has been designed to perform experiments at pressures and temperatures up to, respectively $40 \mathrm{MPa}$ and $473.15 \mathrm{~K}$. The stainless steel tube (1) $(10 \mathrm{ml})$ was previously loaded with a known volume of DMSO taking into account the volumetric expansion upon introduction of $\mathrm{CO}_{2}$. The stirring device was composed of one stainless steel ball moved with magnets outside the tube. $\mathrm{CO}_{2}$ was introduced into the cell (1) at desired temperature (T) and pressure (P) by the syringe pump (ISCO Model 260D). Temperature of the pump was controlled by a thermostatic bath within $\pm 0.01 \mathrm{~K}$. Cell (1) and all pipes from the valve $\mathrm{V}-2$ to the valve V-6 were thermally controlled within $\pm 0.1 \mathrm{~K}$ by means of a heating tape. Once the equilibrium was reached, the valve V-3 was slowly opened in order to refill the vibrating U-tube densimeter (Anton-Paar Model DMA-HPM) (2). Temperature in the vibrating U-tube was precisely controlled by a thermostatic bath within $\pm 0.01 \mathrm{~K}$ and pressure was measured by a transducer (Druck Model PTX 611) with an accuracy of $\pm 0.001 \mathrm{MPa}$. After the sampling, a new equilibrium time was reached quickly because of the small volume of the loop and the care brought to this operation. 
In this work, the vibrating U-tube densimeter was previously calibrated with water and nitrogen for all the pressure and temperature range of the volumetric expansion measurements. The principle of density measurements using this technology is based on the dependence of the vibration period of the Ubended part of the tube according to the filling fluid mass and the U-tube mass. The behaviour of the vibrating tube can be compared to an undamped springmass, defined by its oscillation period, $\tau(\mathrm{s})$, such as:

$\tau=2 \pi \sqrt{\frac{m_{o}+V \rho}{D}}$

where $\mathrm{m}_{0}$ is the mass of the empty U-tube $(\mathrm{kg}), \mathrm{V}$ is the internal volume of the tube $\left(\mathrm{m}^{3}\right), \rho$ is the density of the fluid $\left(\mathrm{kg} \cdot \mathrm{m}^{-3}\right)$ and D is the spring constant $\left(\mathrm{N} \cdot \mathrm{m}^{-}\right.$ $\left.{ }^{1}\right)$. Rearrangement of this equation leads to a simple relation giving the density commonly used in the vibrating tube technology:

$\rho=A \tau^{2}-B$

The apparatus parameters A and B are defined from measured oscillation periods at fixed pressure and temperature conditions and known densities of water (Wagner et al., 2002) and nitrogen (Span et al., 2000), such as:

$$
\begin{aligned}
& A=\frac{\rho_{H_{2} O(T, P)}-\rho_{N_{2}(T, P)}}{\left(\tau_{H_{2} O(T, P)}\right)^{2}-\left(\tau_{N_{2}(T, P)}\right)^{2}} \\
& B=\frac{\left(\tau_{N_{2}(T, P)}\right)^{2} \rho_{H_{2} O(T, P)}-\left(\tau_{H_{2} O(T, P)}\right)^{2} \rho_{N_{2}(T, P)}}{\left(\tau_{H_{2} O(T, P)}\right)^{2}-\left(\tau_{N_{2}(T, P)}\right)^{2}}
\end{aligned}
$$

It is important to note that measured oscillation periods and consequently the measured densities were very sensitive to pressure and temperature variations. Thanks to the compensation of the syringe pump (about $\pm 0.01 \mathrm{ml} / \mathrm{min}$ ) and the good precision of the several heating devices of the VLE apparatus, we obtained a good stability of the thermodynamic equilibrium and reliable density measurements, which were repeated at least twice with an overall precision of $\pm 0.48 \mathrm{~kg} \cdot \mathrm{m}^{-3}$. 


\subsubsection{Viscosity measurements}

A schematic diagram of the falling body viscosimeter (FBV) is shown on Figure 5. The apparatus has been designed to perform experiments at pressures and temperatures up to, respectively $44 \mathrm{MPa}$ and $473.15 \mathrm{~K}$. The stainless steel autoclave with a capacity of 2.61 (Top-industrie, France) was previously loaded with DMSO and heated to the desired temperature. It was equipped with sapphire windows (SW) for visualization purpose using a cold lighting device and a high speed digital video camera (Photron, USA) connected to a computer. Liquid $\mathrm{CO}_{2}$ was pumped with a high pressure membrane pump (Lewa, France) and preheated by a heat exchanger (Separex, France) before flowing into the autoclave equipped with a mechanical stirrer (Top-industrie, France). Then, a syringe pump (ISCO Model 100HLX) previously filled with DMSO and operating at the same temperature as in the autoclave, adjusted the level of the liquid phase (because of its expansion) so as to immerge totally the glass tube. The pressure and temperature set-up of the viscosimeter were kept constant within $\pm 0.1 \mathrm{MPa}$ and $\pm 0.1 \mathrm{~K}$.

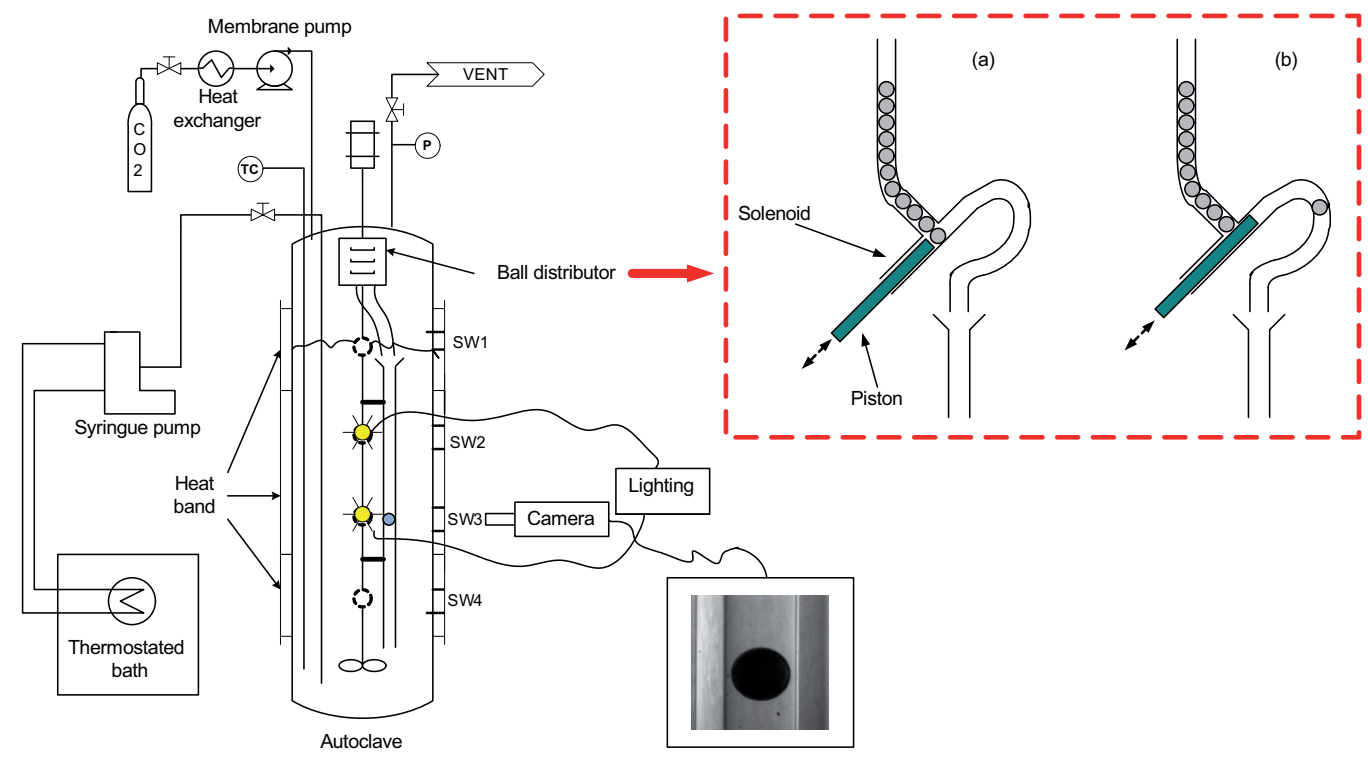

Figure 5. Schematic diagram of the high pressure viscosimeter

Once the equilibrium was reached, stirring was stopped and viscosity measurements were performed at constant pressure and temperature. Measurements consisted in recording through a window (SW3) the fall of an aluminium ball ( $2 \mathrm{~mm}$ diameter) in an open glass tube $(2.1 \mathrm{~mm}$ diameter and 20 $\mathrm{cm}$ length). The ball distributor allowed to release them one at a time by means of 
an electrical impulsion given to the solenoid (Figure 5(a) and 5(b)). The first ones were not considered and ensured the homogenization of the fluid in the tube, even if the whole volume in the autoclave was previously homogenized during 24 hours.

A detailed description of the methodology for viscosity determination by CFD calculation under COMSOL Multiphysics ${ }^{\circledR}$ has recently been reported elsewhere (Calvignac et al., 2009b). Calculations were based on the laminar Navier-Stokes model for a newtonian fluid and on the continuity equation for an incompressible fluid, both in steady-state conditions. The key experimental parameters for these calculations were the ball terminal velocity, the fluid density and the ball density. The terminal velocities were obtained by the analysis of the images of a high-speed digital video using software developed with the Image Processing Toolbox from Matlab ${ }^{\circledR}$. The fluid density data were taken from the measurements done in this work. The density of the aluminium ball $2723.3 \pm 0.9$ $\mathrm{kg} . \mathrm{m}^{-3}$, was previously determined by a $\mathrm{He}$ pycnometer. Prior to these measurements, we performed rheological measurements at atmospheric pressure on DMSO with a dynamic rotational rheometer (Haake Rheostress 600, Thermo electron, Germany) with a cone-plate geometry $\left(1^{\circ}\right.$ angle cone and $60 \mathrm{~mm}$ diameter). They allowed measuring viscosity of pure DMSO from 298 to $318 \mathrm{~K}$, which was compared to the results obtained with the falling body viscosimeter (FBV) and to the literature data.

\section{Results and Discussion}

\subsection{Vapour-Liquid equilibrium of $\mathrm{CO}_{2}$-DMSO system}

\subsubsection{Volumetric Expansion}

Expansion of DMSO with $\mathrm{CO}_{2}$ was measured at 298 and $308 \mathrm{~K}$ and the results are presented in Table 2. Several investigators also measured the volumetric expansion at $298 \mathrm{~K}$ (Kordikowski et al., 1995; Elvassore et al., 2002; Rajasingam et al., 2004) and $308 \mathrm{~K}$ (Yeo et al., 1993; Rajasingam et al., 2004) and their data are compared to ours in Figure 6 and 7. Kordikowski et al. leaned on the densities measurements using the vibrating tube technology to determine the volumetric expansions with the same equation (1). Elvassore et al. used the UV-Vis spectroscopy to determine expansion of DMSO from the on-line monitoring of the concentration of $\mathrm{CO}_{2}$. Indeed, the Beer-Lambert law allowed linking the variation of the absorbance signal to the concentration, which is directly related to the volumetric expansion. Our measurement method is similar to that used by Yeo et al. who determined the volumetric expansion by visual observation. 
Rajasingam et al. used the same method, except that the equilibrium was reached by recirculation of the liquid phase using a metering pump.

For all authors, the evolution of expansion according to the pressure is similar. The expansion increases slowly until a pressure of $5 \mathrm{MPa}$ at $298 \mathrm{~K}(6.5$ $\mathrm{MPa}$ at $308 \mathrm{~K}$ ) and then drastically above this pressure. This evolution at high pressure induces a technical limit: the expansion becomes so important that it is no longer possible to visualize the interface beyond the pressure range investigated. Futhermore, some authors assert that in this region where $\mathrm{CO}_{2}$ concentration is high, a transition from a two-phase $(\mathrm{L}-\mathrm{V})$ to a three-phase (L-LV) occurs (Andreatta et al., 2007; Vega Gonzalez et al. 2002).

At a given pressure, the expansion of DMSO with $\mathrm{CO}_{2}$ decreases when temperature increases. It is due to the drop of both the density and the solubility of $\mathrm{CO}_{2}$ with temperature. At $298 \mathrm{~K}$, our results are consistent with the results of Rajasingam et al. $(\mathrm{MD}=13.5 \%)$ and Elvassore et al. $(\mathrm{MD}=4.9 \%)$. MD represents the mean deviation between literature data and ours. At $308 \mathrm{~K}$, there is a significant deviation between our results and those of Rajasingam et al. The accordance between Yeo's results and ours depends on the experimental pressure. Particularly, they are in good agreement in the high-pressure range. Note that there are discrepancies in this zone between Rajasingam et al and Yeo et al, which are explained by Rajasingam et al. according to a different equilibration time in spite of similar techniques used. This may not be a satisfying explanation since we have the same equilibration time as Rajasingam et al. whereas our volumetric expansion results are close to those of Yeo et al.

Finally, the reliability of our method could be confirmed since the error on the volumetric expansion determination, $\Delta \mathrm{E}$, was less than $4 \%$, leading to narrow confidence intervals on volumetric expansion given in Table 2 and Figures 6 and 7 .

$\Delta E=E \cdot\left(\frac{\Delta V}{V}+\frac{2 \Delta V_{0}}{V_{0}}\right)$

with $\Delta V=V \cdot\left(\frac{\Delta H}{H}\right)$

where $\Delta V$ is the measurement uncertainty of the volume $(\mathrm{ml}), \Delta H$ is the measurement uncertainty of the height of liquid (pixel), $\Delta V_{0}$ is the measurement uncertainty of the initial volume $(\mathrm{ml})$ introduced by the syringe pump. 
Table 2. Volumetric expansion of DMSO with $\mathrm{CO}_{2}$ at different pressures at 298 and $308 \mathrm{~K}$

\begin{tabular}{|c|c|c|c|}
\hline \multicolumn{2}{|c|}{$298 \mathrm{~K}$} & \multicolumn{2}{|c|}{$308 \mathrm{~K}$} \\
\hline $\mathbf{P}$ (MPa) & E (\%) & $\mathbf{P}(\mathrm{MPa})$ & E (\%) \\
\hline 2.66 & $15.66 \pm 0.24$ & 2.01 & $5.86 \pm 0.02$ \\
\hline 3.00 & $20.97 \pm 0.29$ & 3.03 & $14.31 \pm 0.04$ \\
\hline 3.98 & $40.56 \pm 0.44$ & 4.04 & $25.38 \pm 0.07$ \\
\hline 4.50 & $55.83 \pm 0.52$ & 5.04 & $40.67 \pm 0.11$ \\
\hline 5.05 & $88.04 \pm 0.65$ & 6.04 & $65.39 \pm 0.17$ \\
\hline 5.50 & $138.17 \pm 0.81$ & 7.03 & $118.42 \pm 0.29$ \\
\hline 5.81 & $281.59 \pm 1.15$ & 7.56 & $230.01 \pm 0.52$ \\
\hline 5.91 & $372.07 \pm 12.18$ & 7.59 & $267.10 \pm 0.59$ \\
\hline 6.1 & $828.57 \pm 12.85$ & & \\
\hline 6.2 & $1638.65 \pm 20.24$ & & \\
\hline
\end{tabular}

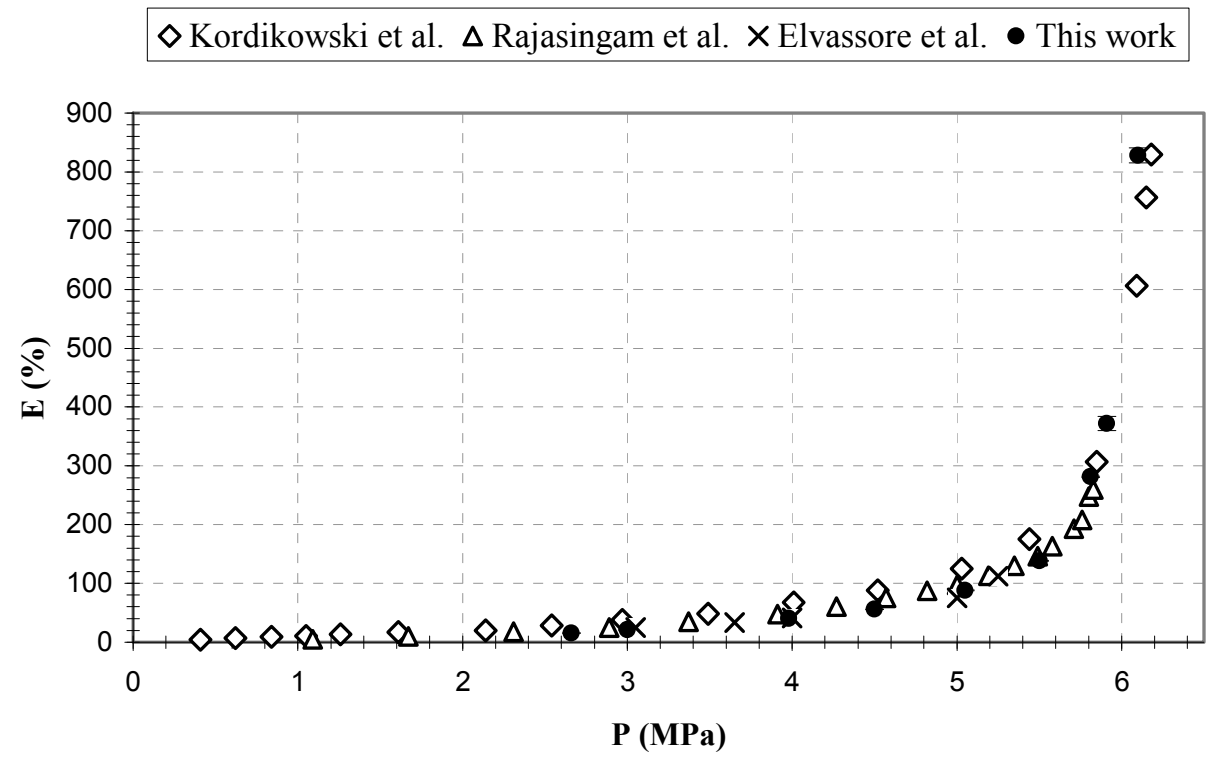

Figure 6. Comparison of volumetric $\mathrm{CO}_{2}$-DMSO expansion with literature data at $298 \mathrm{~K}$ 
$\Delta$ Rajasingam et al. $\times$ Yeo et al. $\bullet$ This work

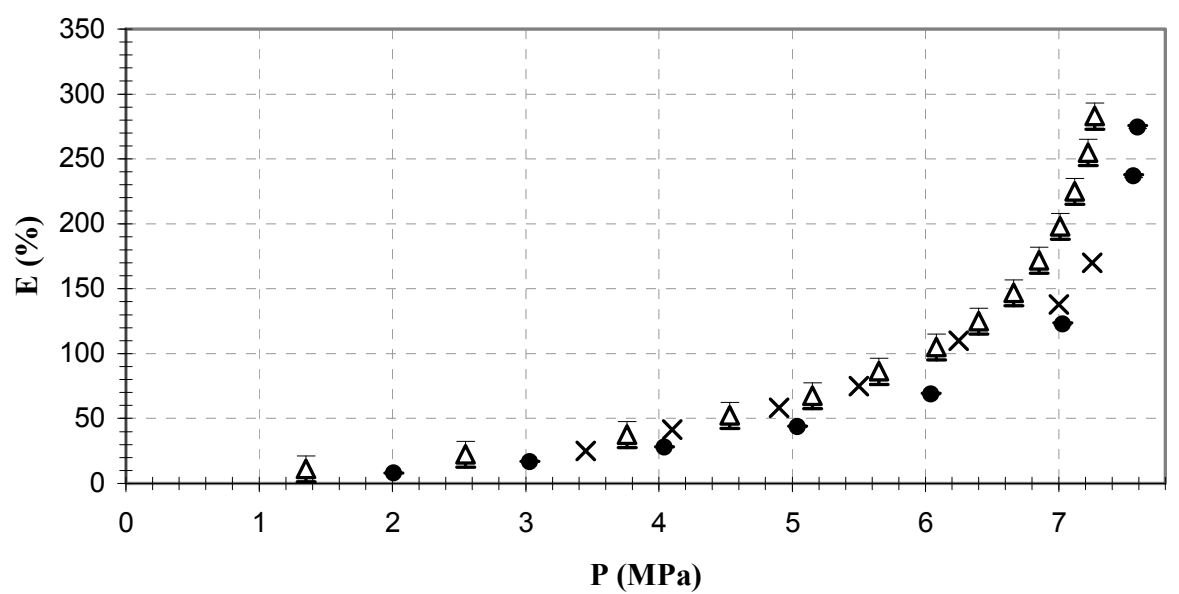

Figure 7. Comparison of volumetric $\mathrm{CO}_{2}$-DMSO expansion with literature data at $308 \mathrm{~K}$

\subsubsection{Solubility of $\mathrm{CO}_{2}$}

Solubility of $\mathrm{CO}_{2}$ in DMSO was measured at 298 and $308 \mathrm{~K}$ with both apparatuses and is presented in Table 3. Several investigators have also determined the phase equilibrium of DMSO-CO $\mathrm{CO}_{2}$ binary at $298 \mathrm{~K}$ and $308 \mathrm{~K}$ (Kordikowski et al., 1995; Vega Gonzales et al., 2002; Andreatta et al., 2004; Rajasingam et al., 2004) and the data are presented in Figure 8 and 9. Kordikowski et al. used a phase separation method, which consisted in sampling a known volume of liquid mixture and in degassing it in a cell. Solubility was calculated considering that the vapour pressure of DMSO could be neglected. Rajasingam et al. used a similar technique, except that the separation was carried out in a solvent trap filled with ethanol. The solution was then analysed by gas chromatography in order to determine the DMSO content. The amount of $\mathrm{CO}_{2}$ was measured with a burette connected to the solvent trap. On the other hand, Vega Gonzales et al. and Andreatta et al. used synthetic methods based on observation of phase transition.

All the results confirm that, above $5 \mathrm{MPa}$ at $298 \mathrm{~K}(6.5 \mathrm{MPa}$ at $308 \mathrm{~K})$, $\mathrm{CO}_{2}$ solubility is high, above $40 \%$ in mass at $298 \mathrm{~K}(50 \%$ in mass at $308 \mathrm{~K})$.

At a given pressure, the solubility of $\mathrm{CO}_{2}$ in DMSO decreases with temperature as for usual gas behaviour. At $298 \mathrm{~K}$, our results are in good agreement with those of Kordikowski et al. $(\mathrm{MD}=0.75 \%)$ but appear lower than the results obtained by Andreatta et al. around $6 \mathrm{MPa}$. At $308 \mathrm{~K}$, data of $\mathrm{CO}_{2}$ solubility are consistent with most of the published data on the whole range of 
pressure $(\mathrm{MD}=3 \%)$. However, for both isotherms, there are significant discrepancies with data obtained by Rajasingam et al. It might be due to an underestimation by these authors of the amount of $\mathrm{CO}_{2}$ dissolved in DMSO, which could be due to losses of $\mathrm{CO}_{2}$ when dissolving into ethanol. Our investigations show that whatever the technique used and even if the measurement principle is not the same, data obtained are in good agreement with synthetic methods $(\mathrm{MD}=2.85 \%)$. This suggests that device 1 and 2 are equivalent and that sampling in device 1 had not disturbed the mixture in equilibrium conditions.

Table 3. Solubility of $\mathrm{CO}_{2}$ in DMSO at different pressures at 298 and $308 \mathrm{~K}$

\begin{tabular}{|c|c|c|c|}
\hline \multicolumn{2}{|c|}{ 298 K - Device 2 } & \multicolumn{2}{|c|}{ 308 K - Device 1 } \\
\hline P (MPa) & $\mathbf{x}_{\mathbf{C O 2}} \mathbf{( \% )}$ & P (MPa) & $\mathbf{x}_{\mathbf{C O 2}} \mathbf{( \% )}$ \\
\hline 4.17 & 29.04 & 3.02 & 17.40 \\
\hline 5.07 & 41.19 & 4.99 & 31.53 \\
\hline 5.9 & 61.60 & 7.03 & 59.85 \\
\hline \multicolumn{2}{|r|}{} & 7.45 & 75.73 \\
\cline { 2 - 4 }
\end{tabular}

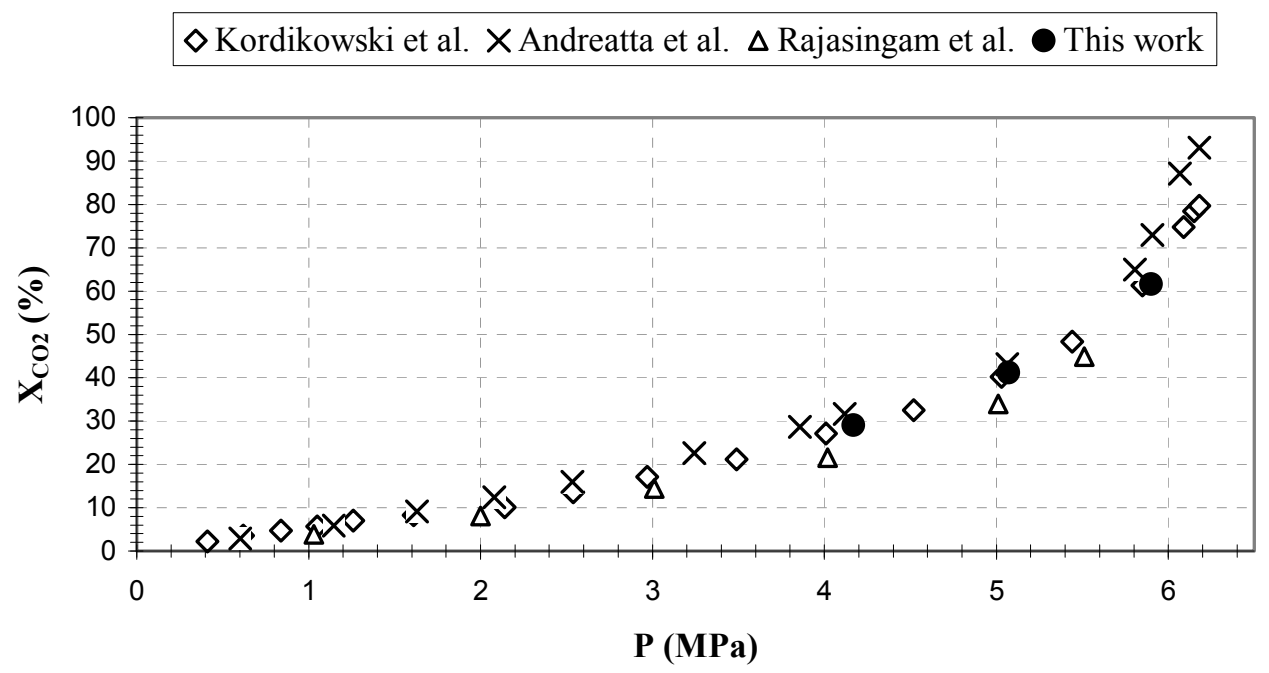

Figure 8. Comparison of $\mathrm{CO}_{2}$ solubility in DMSO with literature data at $298 \mathrm{~K}$ 
$\diamond$ Andreatta et al. $\times$ Vega Gonzales et al. $\Delta$ Rajasingam et al. This work

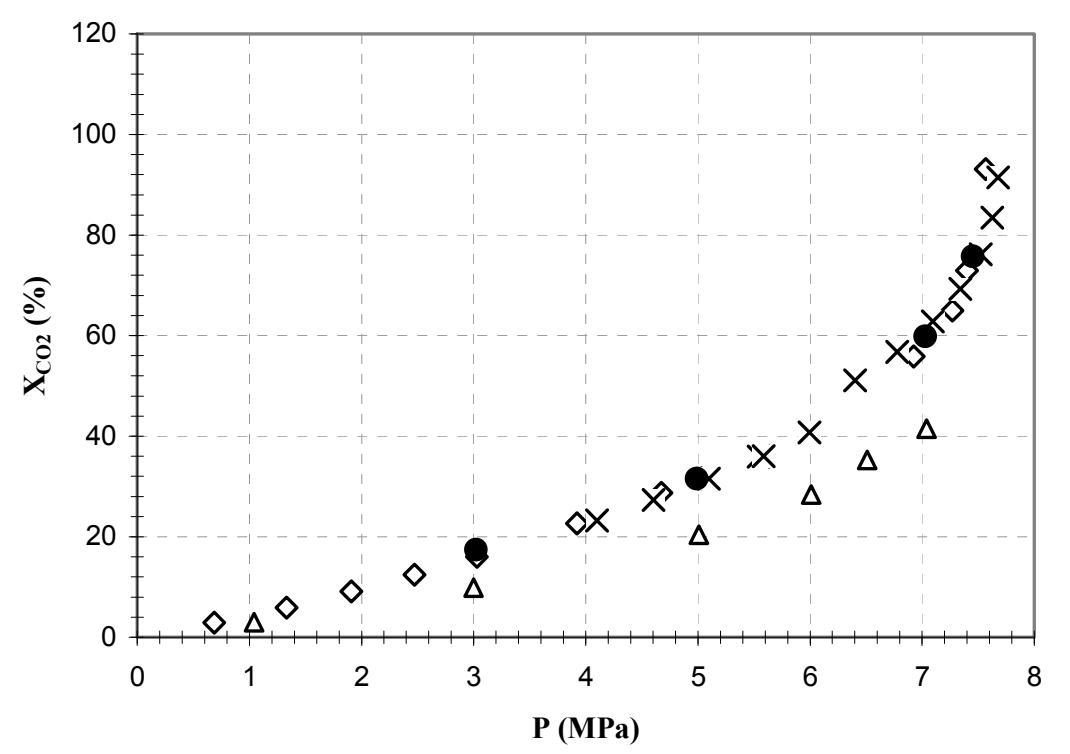

Figure 9. Comparison of $\mathrm{CO}_{2}$ solubility in DMSO with literature data at $308 \mathrm{~K}$

\subsection{Physical properties of $\mathrm{CO}_{2}$-DMSO system}

\subsubsection{Density}

The densities for the liquid phase of the DMSO- $\mathrm{CO}_{2}$ mixture were measured at 298, 308 and $318 \mathrm{~K}$ and they are presented in table 4 and figure 10.

As a comment on the technique used, the density measurement itself is a rather precise one. The main source of deviation on the data obtained (precision: $0.48 \mathrm{~kg} . \mathrm{m}^{-3}$ ) comes from the difficulty to convey the mixture from the bulk in equilibrium conditions towards the vibrating tube without perturbing this mixture. That is why we designed a cell (stainless steel tube previously presented) placed very close to the vibrating tube. No data obtained with different techniques were found in literature. Hence, we could not estimate the validity of our results.

The density decreases with temperature at constant pressure and decreases with the pressure at a given temperature. The variations of density versus pressure can be represented with a fourth-order polynomial regression as it is shown in figure 10 and according to:

$\rho_{c a l}=d_{4} \cdot P_{r e l}^{4}+d_{3} \cdot P_{r e l}{ }^{3}+d_{2} \cdot P_{r e l}{ }^{2}+d_{1} \cdot P_{r e l}+d_{0}$ 
where $d_{1}, d_{2}, d_{3}$ and $d_{4}$ are the fitting parameters without physical meaning, except $d_{0}$, which is the density of pure DMSO at given temperature and atmospheric pressure. $P_{r e l}$ corresponds to the relative pressure in equation (9).

Table 4. $\mathrm{CO}_{2}$-DMSO density measurements at 298,308 and $318 \mathrm{~K}$

\begin{tabular}{|c|c|c|c|c|c|}
\hline \multicolumn{2}{|c|}{$298 \mathrm{~K}$} & \multicolumn{2}{|c|}{$308 \mathrm{~K}$} & \multicolumn{2}{|c|}{$318 \mathrm{~K}$} \\
\hline P (MPa) & $\rho\left(\mathrm{kg} \cdot \mathrm{m}^{-3}\right)$ & P (MPa) & $\rho\left(\mathrm{kg}^{2} \mathrm{~m}^{-3}\right)$ & P (MPa) & $\rho\left(\mathrm{kg}^{2} \mathrm{~m}^{-3}\right)$ \\
\hline 0.10 & 1096.37 & 0.10 & 1084.63 & 0.10 & 1074.93 \\
\hline 0.94 & 1096.85 & 0.75 & 1085.48 & 0.65 & 1075.93 \\
\hline 1.27 & 1096.98 & 2.99 & 1085.60 & 2.03 & 1076.61 \\
\hline 2.10 & 1096.77 & 3.99 & 1085.03 & 2.16 & 1076.65 \\
\hline 2.94 & 1097.21 & 4.99 & 1084.57 & 3.07 & 1076.63 \\
\hline 3.06 & 1096.35 & 6.00 & 1081.47 & 4.05 & 1076.58 \\
\hline 4.00 & 1096.95 & 7.00 & 1076.21 & 6.01 & 1075.07 \\
\hline 4.99 & 1092.60 & & & 6.99 & 1071.44 \\
\hline 5.99 & 1072.91 & & & 7.98 & 1068.63 \\
\hline 6.07 & 1066.15 & & & 8.98 & 1061.73 \\
\hline
\end{tabular}

In order to evaluate the performance of this model with regard to the experimental data, we introduced the characteristic quantities as:

$$
\begin{aligned}
& A A D=\frac{1}{N} \sum_{i=1}^{i=N}\left|100 \cdot\left(\frac{\rho_{\text {exp }}-\rho_{\text {cal }}}{\rho_{\text {exp }}}\right)\right| \\
& \operatorname{MaxD}=\operatorname{Max}\left(\left|100 \cdot\left(\frac{\rho_{\exp }-\rho_{c a l}}{\rho_{\text {exp }}}\right)\right|\right) \\
& \text { Bias }=\frac{1}{N} \sum_{i=1}^{i=N} 100 \cdot\left(\frac{\rho_{\exp }-\rho_{c a l}}{\rho_{\text {exp }}}\right)
\end{aligned}
$$

The average absolute deviation $(A A D)$ characterizes the distance between the experimental points and the modelled curve. The average deviation (Bias) characterizes the quality of the distribution of the experimental points on both sides of modelled curve. Maximum deviation $(\operatorname{MaxD})$ characterizes the maximum deviation generated by the model. 
$298 \mathrm{~K} \diamond 308 \mathrm{~K} \times 318 \mathrm{~K}$

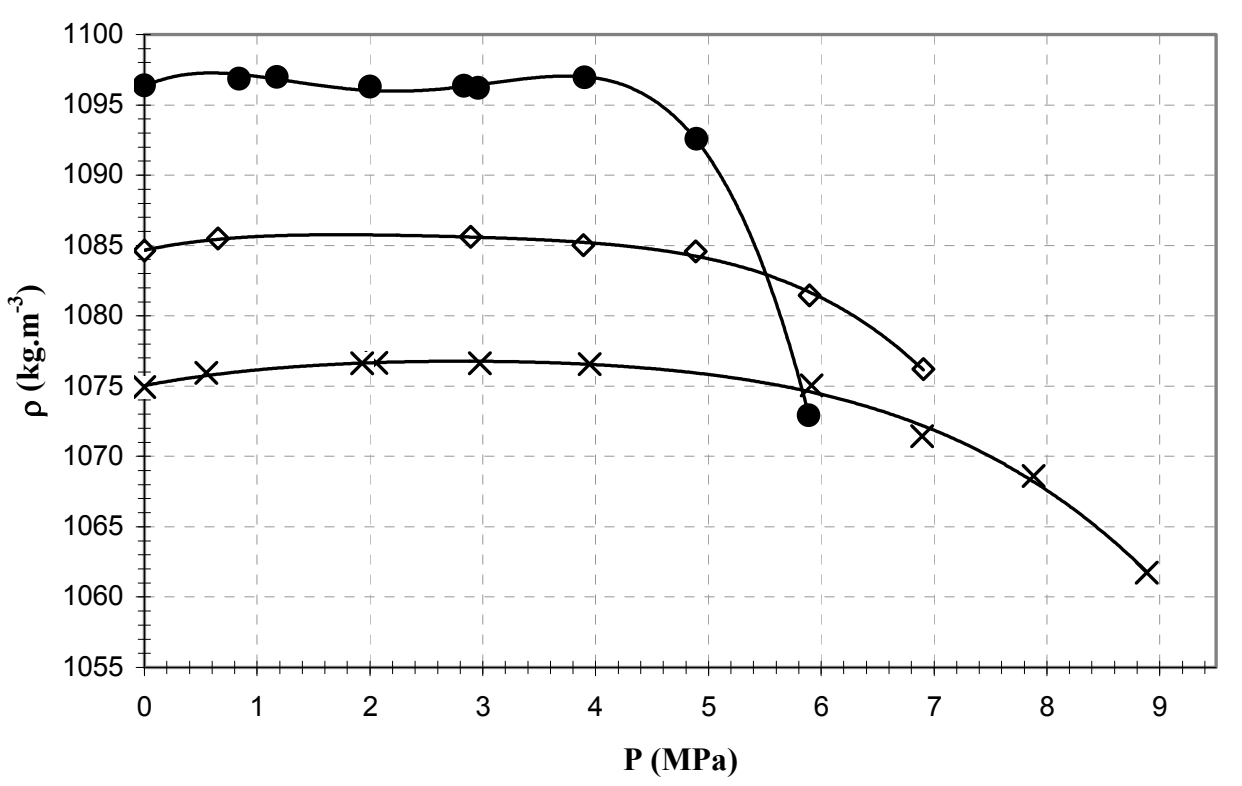

Figure 10. Experimental densities of $\mathrm{DMSO}-\mathrm{CO}_{2}$ at 298,308 and $318 \mathrm{~K}$

Calculated densities given by the model are in very good agreement with experimental data as shown in Figure 10 and Table 5. Indeed, results obtained at $308 \mathrm{~K}$ are satisfactory ( $\mathrm{AAD}=0.011 \%$ ), so is the good distribution of experimental points around the fitting curve. Consequently, these results show that this model is relevant and can be used in this work as a reliable tool for viscosity determination.

Table 5. Fitting parameters and statistics for the density modelling of $\mathrm{CO}_{2}-\mathrm{DMSO}$ mixture

\begin{tabular}{|c|c|c|}
\hline $\mathbf{2 9 8 ~ K}$ & $\mathbf{3 0 8 ~ K}$ & $\mathbf{3 1 8 ~ K}$ \\
\hline $\mathrm{d}_{4}=-2.25405 \times 10^{-1}$ & $\mathrm{~d}_{4}=-2.13442 \times 10^{-2}$ & $\mathrm{~d}_{4}=-6.56705 \times 10^{-3}$ \\
$\mathrm{~d}_{3}=2.097265$ & $\mathrm{~d}_{3}=2.31784 \times 10^{-1}$ & $\mathrm{~d}_{3}=7.69829 \times 10^{-2}$ \\
$\mathrm{~d}_{2}=-6.14226$ & $\mathrm{~d}_{2}=-1.02133$ & $\mathrm{~d}_{2}=-5.05032 \times 10^{-1}$ \\
$\mathrm{~d}_{1}=5.81906$ & $\mathrm{~d}_{1}=1.92917$ & $\mathrm{~d}_{1}=1.63038$ \\
$\mathrm{~d}_{0}=1.09571 \times 10^{3}$ & $\mathrm{~d}_{0}=1.084447 \times 10^{3}$ & $\mathrm{~d}_{0}=1.07488 \times 10^{3}$ \\
$\mathrm{AAD}=0.052 \%$ & $\mathrm{AAD}=0.011 \%$ & $\mathrm{AAD}=0.021 \%$ \\
$\mathrm{MaxD}=0.187 \%$ & $\mathrm{MaxD}=0.031 \%$ & MaxD $=0.071 \%$ \\
Bias $=-3.020 \times 10^{-4} \%$ & Bias $=-3.178 \times 10^{-5} \%$ & Bias $=-1.51 \times 10^{-4} \%$ \\
\hline
\end{tabular}


For each isotherm, Figure 10 shows a slight increase of density when pressure is in the range $0-4 \mathrm{MPa}$. This observation can be attributed to the dissolution of $\mathrm{CO}_{2}$ together with a moderate volumetric expansion. Then, as it is shown in figure 11 and 12, a significant decrease of density begins from $4.5 \mathrm{MPa}$ at $298 \mathrm{~K}$ and $5 \mathrm{MPa}$ at $308 \mathrm{~K}$ because of the drastic increase of the volumetric expansion. Indeed, in these pressure and temperature conditions, the dissolved quantity of $\mathrm{CO}_{2}$ is about $30 \%$ in mass (Figure 13). At $318 \mathrm{~K}$ and around $6 \mathrm{MPa}$, the same behaviour can be observed with regard to the $\mathrm{CO}_{2}$ solubility. In figure 13, as our solubility values are in accordance with those of Kordikowski et al. at $298 \mathrm{~K}$ and Andreatta et al. at $308 \mathrm{~K}$, which are available in a wider range of pressure than ours. Furthermore, solubility data of Andreatta et al. at $318 \mathrm{~K}$ have been preferred to those of Rajasingam et al. because these last ones have discrepancies with our results at 298 and $308 \mathrm{~K}$.

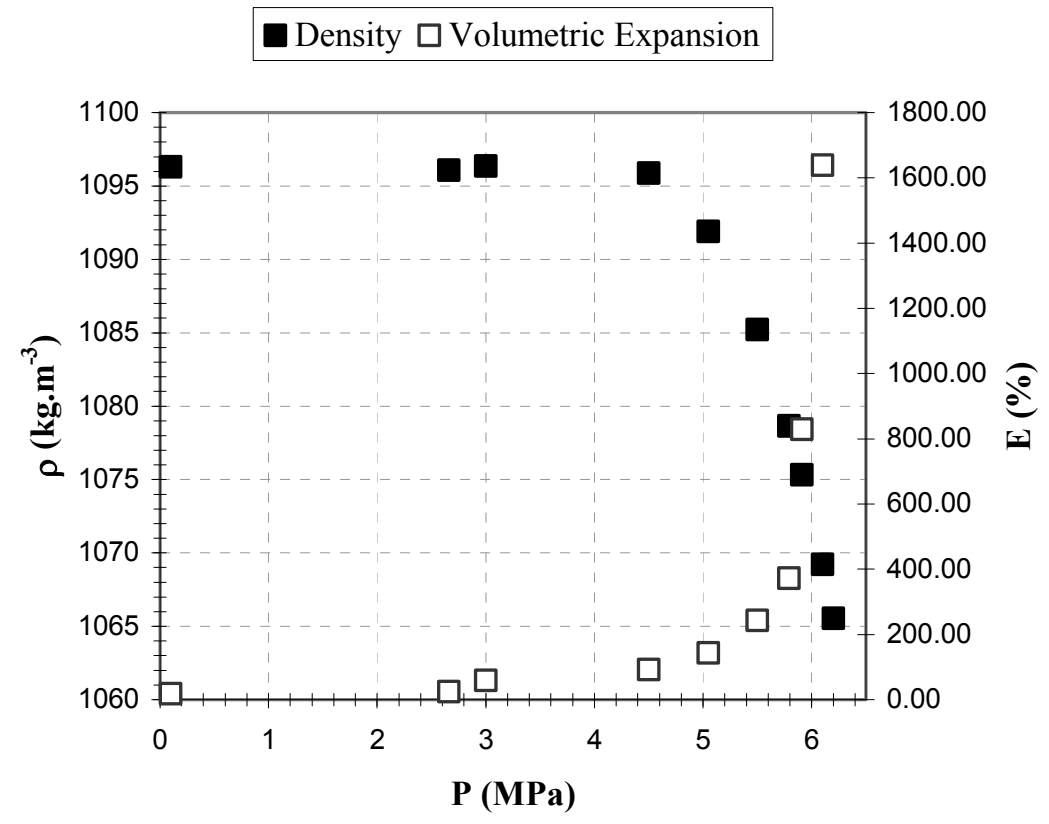

Figure 11. Evolution of liquid density of $\mathrm{DMSO}-\mathrm{CO}_{2}$ and its volumetric expansion at $298 \mathrm{~K}$ 


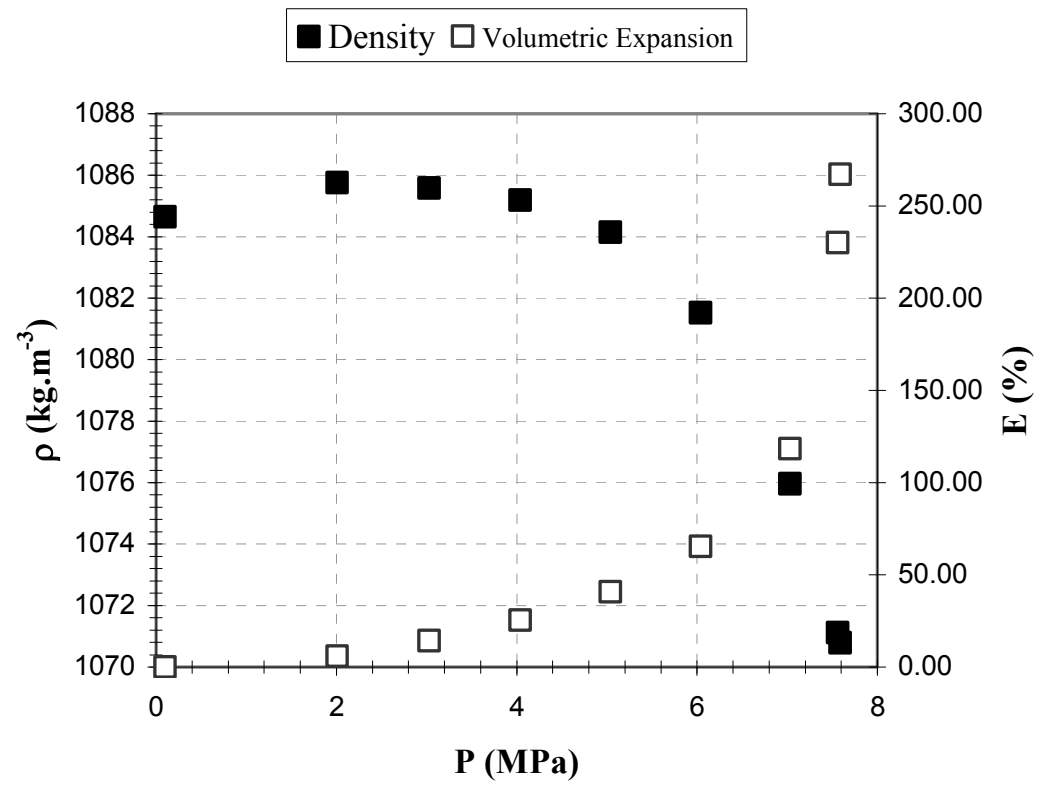

Figure 12. Evolution of liquid density of DMSO-CO $\mathrm{CO}_{2}$ and its volumetric expansion at $308 \mathrm{~K}$

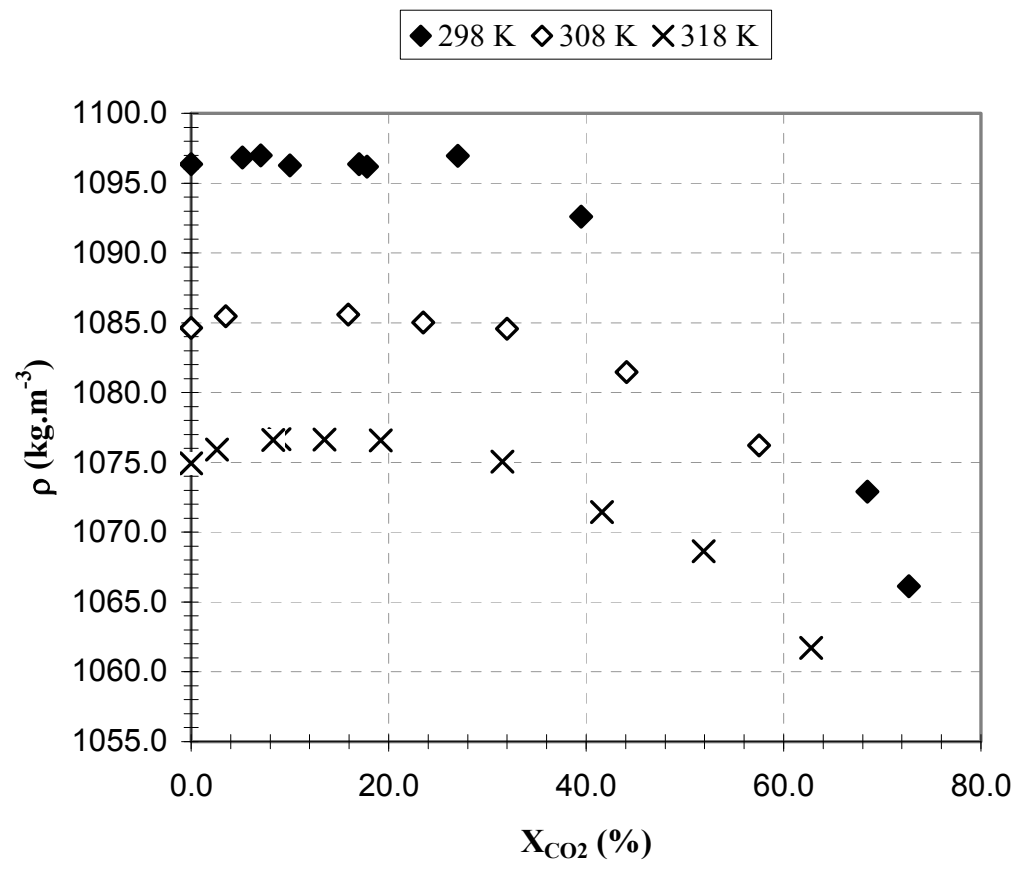

Figure 13. Evolution of liquid density of DMSO-CO $\mathrm{CO}_{2}$ with the $\mathrm{CO}_{2}$ solubility 


\subsubsection{Viscosity}

Viscosities were measured for the liquid phase of DMSO-CO $\mathrm{CO}_{2}$ binary for pressure ranging from 0.1 to $7.4 \mathrm{MPa}$ at 298,308 and $318 \mathrm{~K}$. Results obtained are presented in Table 6 and Figure 14. Before these investigations, we performed rheological measurements of pure DMSO at atmospheric pressure for each isotherm with a dynamic rotational rheometer. It permitted to validate our viscosity measurements obtained with the FBV at atmospheric pressure and to compare to literature data (Figure 15).

DMSO is a newtonian fluid and its viscosity decreases exponentially with temperature (Kapoor et al., 1999; Bhuiyan et al., 2007). Measurements obtained at atmospheric pressure and $318 \mathrm{~K}$ with the FBV are slightly different from those obtained with rotational rheometry and by Bhuiyan et al. On the other hand, no experimental data about viscosity of the DMSO- $\mathrm{CO}_{2}$ under pressure are available in literature. At given temperature, viscosity of the liquid phase decreases exponentially with the pressure due to the dissolved amount of $\mathrm{CO}_{2}$, as it is shown in Figure 14 and 16. The magnitude of the decrease in viscosity is about $75 \%$ for each isotherm at the maximal pressure investigated. Figure 16 shows the great influence of the $\mathrm{CO}_{2}$ solubility, given that we used the same literature solubility values as in Figure 13. Figure 14 shows that the higher the temperature, the lower the viscosity until the inversion zone around $3.5 \mathrm{MPa}$ for a viscosity of about 0.8 mPa.s. Besides, in the same way, Figure 16 shows the same tendency until the inversion zone for a liquid phase composition in $\mathrm{CO}_{2}$ around $38 \%$ (in mass) and for a viscosity about $0.5 \mathrm{mPa}$.s (Figure 17). Measurements were repeated 5 times for each pressure and temperature condition.

The limitations of the FBV technique were investigated and are presented elsewhere (Calvignac et al., 2009b). They include mainly the necessity to work with a transparent medium, the limited range of terminal velocity captured by the optical device, axisymmetry and steady flow requirements $(\operatorname{Re}<210)$ and terminal velocity which may not be attained at the visualization height. The optical device features and image analysis requirements impose a maximal terminal velocity of $35 \mathrm{~mm} . \mathrm{s}^{-1}$. Considering table 6 , we see that our velocity values are compatible with this limitation. In addition, the flow has to be steady at the visualization height (at half length of the tube). The model hypotheses, axisymmetry and steady flow, require to maintain the Reynolds number below 210. For the highest pressures of the three isotherms, in table 6, the Reynolds number is above this limiting value. This last one was in fact established for the flowing of a solid sphere in a medium that could be considered as infinite. In such conditions and for Reynolds numbers above 210, the flow is no more axisymmetric and may not be steady anymore. Yet, due to the ratio between the ball diameter and the tube, which is about 0.96 , we are here in confined, restrained flow conditions. The flow 
streamlines may be so stabilized and the Reynolds number limiting value is probably moved towards higher value, which has not been calculated yet.

Given all these limitations, the FBV can be used on a wide range of viscosities and measurements on DMSO allowed to test the lowest range: viscosities as low as $0.3 \mathrm{mPa}$.s could then be measured with a good enough precision. The reliability of our method is good with relative standard deviation (RSD) of about $1.9 \%$.

$R S D=100 \cdot \frac{\sqrt{\frac{1}{N} \sum_{i=1}^{i=N}\left(x_{i}-\bar{x}\right)^{2}}}{\bar{x}}$

Table 6 . Viscosity measurements at 298,308 and $318 \mathrm{~K}$

\begin{tabular}{|c|c|c|c|c|}
\hline Temperature (K) & P (MPa) & $\mu$ (mPa.s) & $\boldsymbol{V}_{\text {ball }}\left(\mathbf{m m} . \mathbf{s}^{-1}\right)$ & $\mathbf{R e}$ \\
\hline \multirow{4}{*}{298} & 0.10 & $2.077 \pm 0.069$ & $7.591 \pm 0.253$ & 16 \\
\cline { 2 - 5 } & 0.78 & $1.725 \pm 0.083$ & $9.133 \pm 0.442$ & 23 \\
\cline { 2 - 5 } & 1.99 & $1.275 \pm 0.040$ & $12.346 \pm 0.387$ & 42 \\
\cline { 2 - 5 } & 2.85 & $1.008 \pm 0.035$ & $15.685 \pm 0.461$ & 68 \\
\cline { 2 - 5 } & 3.93 & $0.732 \pm 0.034$ & $21.136 \pm 0.109$ & 127 \\
\cline { 2 - 5 } & 4.95 & $0.471 \pm 0.031$ & $33.711 \pm 0.375$ & 313 \\
\hline \multirow{5}{*}{308} & 0.10 & $1.719 \pm 0.056$ & $9.237 \pm 0.296$ & 23 \\
\cline { 2 - 5 } & 0.80 & $1.609 \pm 0.063$ & $9.862 \pm 0.389$ & 27 \\
\cline { 2 - 5 } & 1.24 & $1.353 \pm 0.028$ & $11.718 \pm 0.242$ & 38 \\
\cline { 2 - 5 } & 2.69 & $1.020 \pm 0.034$ & $15.543 \pm 0.525$ & 66 \\
\cline { 2 - 5 } & 4.78 & $0.623 \pm 0.043$ & $24.585 \pm 0.454$ & 171 \\
\cline { 2 - 5 } & 5.72 & $0.459 \pm 0.012$ & $32.075 \pm 0.237$ & 303 \\
\hline \multirow{5}{*}{318} & 0.10 & $1.476 \pm 0.040$ & $10.814 \pm 0.291$ & 32 \\
\cline { 2 - 5 } & 0.61 & $1.368 \pm 0.050$ & $11.674 \pm 0.428$ & 37 \\
\cline { 2 - 5 } & 1.6 & $1.157 \pm 0.034$ & $13.797 \pm 0.403$ & 51 \\
\cline { 2 - 5 } & 2.94 & $0.915 \pm 0.016$ & $17.406 \pm 0.306$ & 82 \\
\cline { 2 - 5 } & 4.69 & $0.659 \pm 0.024$ & $23.479 \pm 0.866$ & 153 \\
\cline { 2 - 5 } & 7.37 & $0.413 \pm 0.029$ & $35.375 \pm 0.919$ & 367 \\
\hline
\end{tabular}




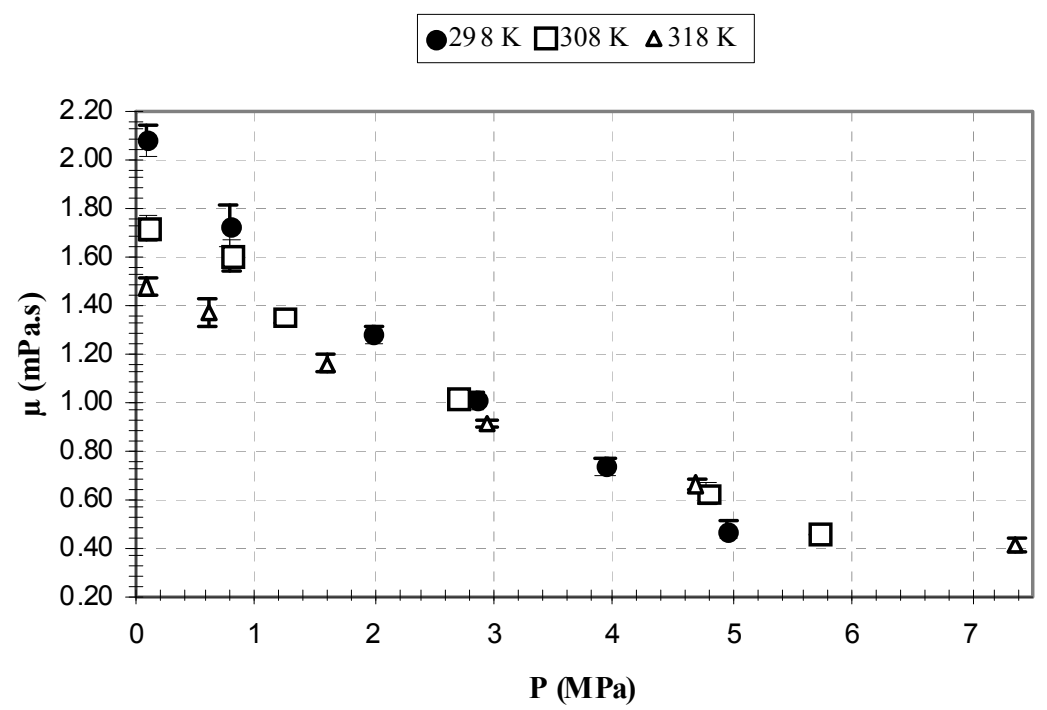

Figure 14. Evolution of liquid viscosities with the pressure of DMSO-CO

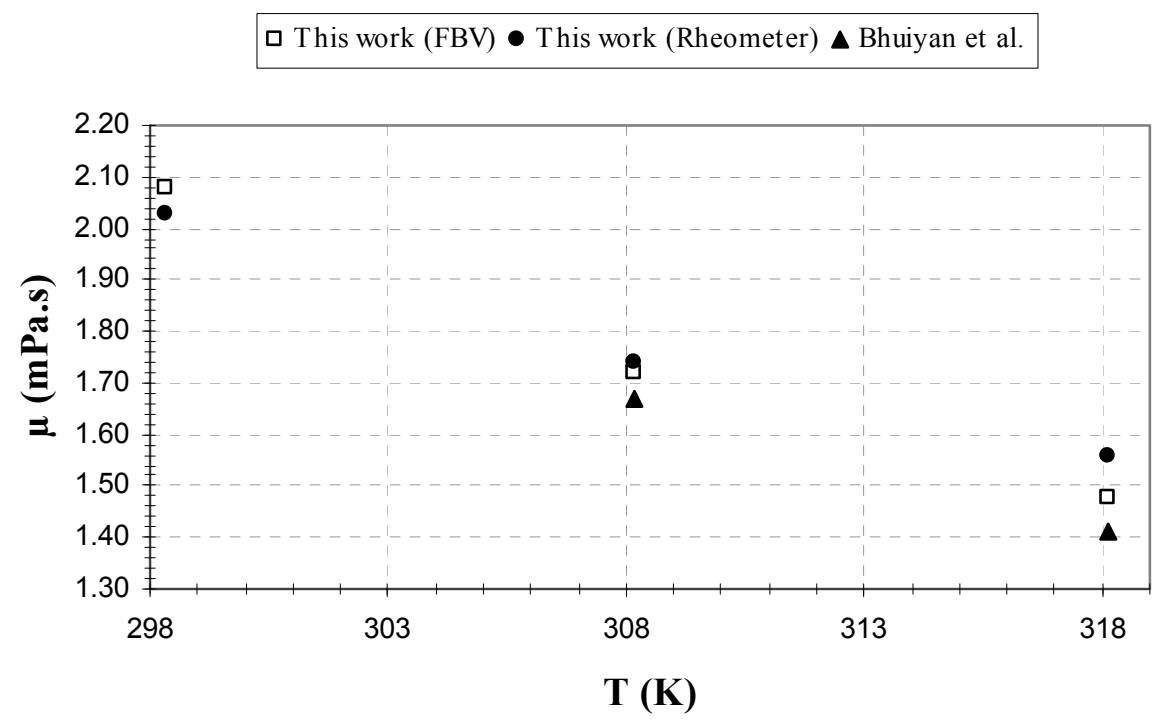

Figure 15. Comparison of pure DMSO viscosities with literature data 


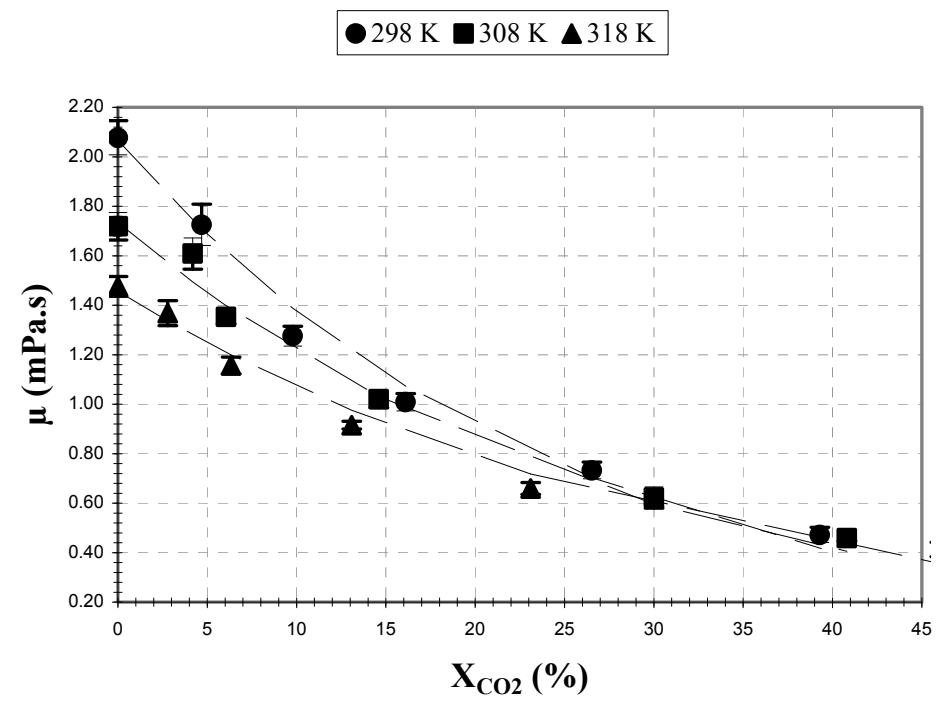

Figure 16. Experimental results of $\mathrm{CO}_{2}$-DMSO liquid viscosities with the $\mathrm{CO}_{2}$ solubility and correlation curves according to relation (14)

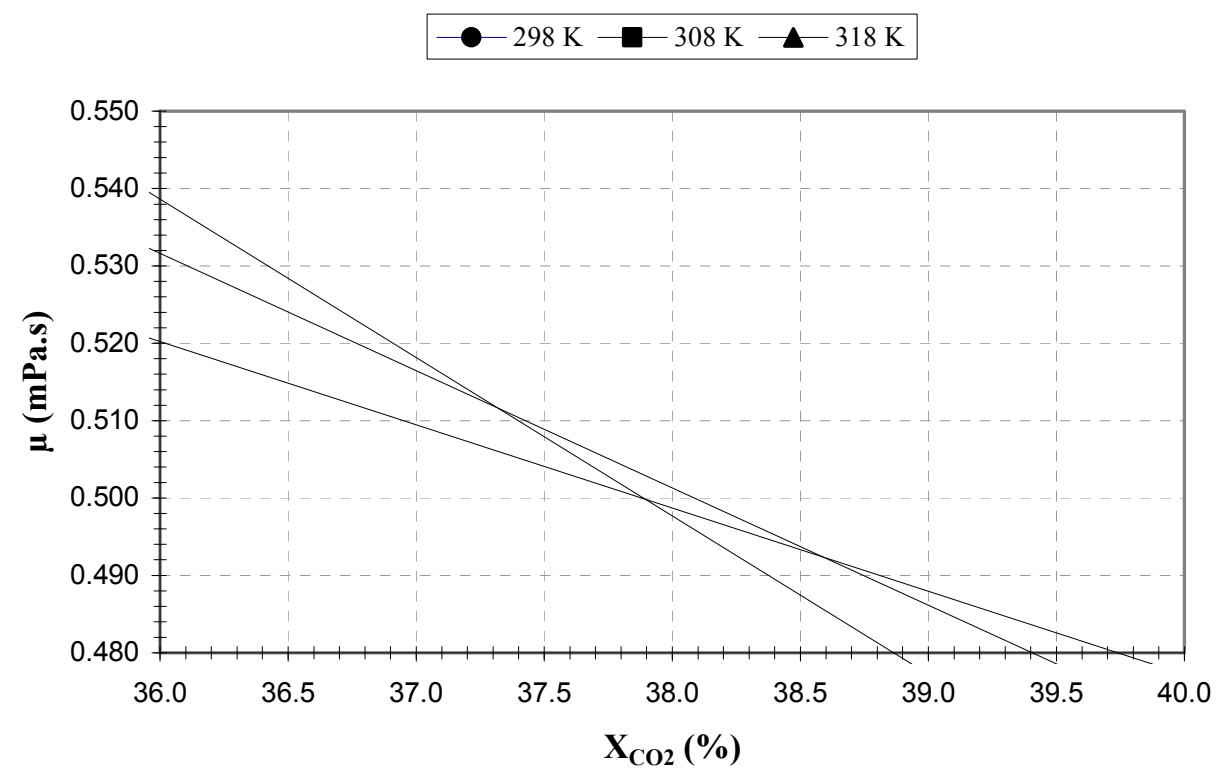

Figure $17 . \mathrm{CO}_{2}$-DMSO viscosity in range of $\mathrm{CO}_{2}$ solubility from 36 to $40 \%$

In addition, dissolution of $\mathrm{CO}_{2}$ inducing the exponential decrease of the viscosity, we proposed a semi-empirical correlation such as: 
$\mu=\underset{(P 0, T)}{\mu_{D M S O}} \cdot \exp \left[A(T) \cdot x_{C O_{2}}\right]$

with $\underset{(P 0, T)}{\mu_{D M S O}}=B \cdot \exp \left\lfloor\frac{E_{a}}{R T}\right\rfloor$

and $A(T)=A_{0}+A_{1} \cdot T$

This model required to use optimization methods such as Levenberg-Marquart algorithm for the determination of the three parameters of the Equation (14). Note that $A(T)$ is a fitting parameter without physical meaning but depending linearly on the temperature. Viscosity of pure DMSO at atmospheric pressure depends on the temperature and follows an Arrhenius-type law (Equation 15) where $B$ is constant and $E_{a}$ represents the activation energy. All fitting parameters of the correlation are given in Table 7.

Table 7. Parameters values and statistics of the viscosity correlation

\begin{tabular}{|c|c|c|c|}
\hline Parameters & AAD (\%) & MD (\%) & Bias (\%) \\
\cline { 1 - 1 }$A_{0}=-19.0250$ & & & \\
\cline { 1 - 1 }$A_{I}=0.0502$ & \multirow{2}{*}{5.6} & \multirow{2}{*}{14.6} & 0.6 \\
\cline { 1 - 1 }$E_{a}=13755.2{\mathrm{~J} . \mathrm{mol}^{-1}}^{-1}$ & & & \\
\cline { 1 - 1 }$B=0.0081 \mathrm{mPa} . \mathrm{s}$ & & & \\
\hline
\end{tabular}

Dashed curves in the Figure 16 show that the correlation fits well the experimental data $(\mathrm{AAD}=5.5 \%)$. The maximal deviation is observed for the highest $\mathrm{CO}_{2}$ concentrations. Nevertheless, the Bias value is only $0.6 \%$, which means that the distribution of the experimental points around the fitting curve is satisfactory.

\section{Conclusion}

New experimental set-up for physical properties measurements have been validated using the binary system $\mathrm{CO}_{2}$-DMSO. Comparisons with literature data have extensively been studied: all the measurements reveal to be in rather good agreement with the already published data even if experimental techniques differ. Our volumetric expansion measurement device is easy to undertake and precise (error less than $4 \%$ on the volumetric expansion measured). Results obtained are in good accordance with literature data for volumetric expansion values up to 100 
\%. Above this value, for high $\mathrm{CO}_{2}$ concentrations, there is not unanimous agreement among all the results.

In solubility measurement methods, we tested the effect of the measurement method, on a sample taken from the bulk or in situ measurement of the bulk, and we found that it had no influence on the results. Besides, all the data obtained are in good agreement whatever the measurement technique used. However, data from Rajasingam et al. differ: their solubility values may be underestimated due the method used.

The density measurement method was found to be reliable $\left( \pm 0.48 \mathrm{~kg} \cdot \mathrm{m}^{-3}\right)$. Even if we did not compare our results to the literature, their evolution is consistent with the evolution of the other properties measured. For instance, it has been shown that density evolution according to pressure is consistent with the volumetric expansion one.

The viscosity measurement is also reliable $( \pm 1.9 \%)$. The operating limitations were investigated: laminar flow, transparent medium, axisymmetric and steady flow conditions and possible visualization below a velocity of 35 $\mathrm{mm} \cdot \mathrm{s}^{-1}$. Even with these limiting features, viscosity could be measured down to $0.3 \mathrm{mPa}$.s. Moreover, we have completed the literature with new values since no viscosity data on the binary mixture studied had ever been published. At last, this work opens new perspectives concerning the determination of physical properties under high pressure. In continuation to this work, some other binary systems are being tested, such as natural products (Calvignac et al., 2009a) and polymers (Vitoux et al., 2008) with $\mathrm{CO}_{2}$.

These new and reliable data on physical properties for the $\mathrm{CO}_{2}$-DMSO mixture can be used for the binary mixture separation and recycling process design. Yet, the antisolvent step of the SAS process requires additional data measurements extended to the ternary mixture including the solute.

\section{Notation}

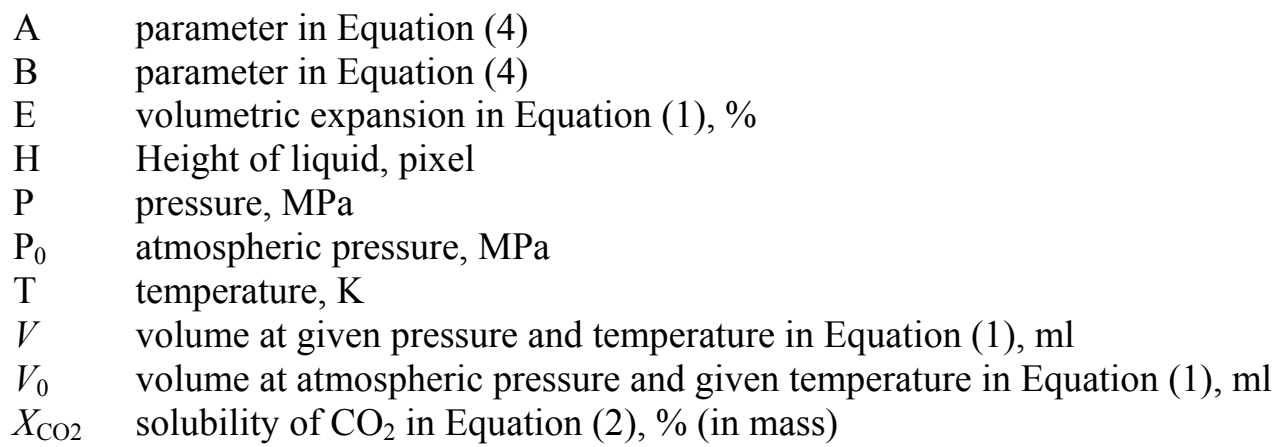


$x_{\mathrm{CO} 2}$ mass proportion of $\mathrm{CO}_{2}$ in Equation (15)

Greek letters

$\rho \quad$ density, kg.m-3

$\rho_{c a l} \quad$ calculated density in Equation (9), kg.m-3

$\tau \quad$ oscillation period, $\mathrm{s}$

Abbreviations

$\begin{array}{ll}\text { AAD } & \text { Absolute Average Deviation } \\ \text { Bias } & \text { Average deviation } \\ \mathrm{CO}_{2} & \text { Carbone Dioxide } \\ \text { DMSO } & \text { Dimethyl Sulfoxide } \\ \text { FBV } & \text { Falling Body Viscosimeter } \\ \text { i.d. } & \text { In diameter } \\ \text { MaxD } & \text { Maximum deviation } \\ \text { MD } & \text { Mean Deviation } \\ \text { o.d. } & \text { Out diameter } \\ \text { RSD } & \text { Relative Standard Deviation } \\ \text { VLE } & \text { Vapour-Liquid Equilibrium }\end{array}$

\section{References}

Andreatta A.E., Florusse L.J., Bottini S.B., Peters C.J., "Phase equilibria of dimethyl sulfoxide (DMSO) + carbon dioxide, and DMSO + carbon dioxide + water mixtures", J. Supercrit. Fluids, 2007, 42, 60-68.

Bertucco A., Vetter G., "High Pressure Technology: Fundamentals and Applications", Elsevier, Oxford, 2001.

Bhuiyan M.M.H., Ferdaush J., Uddin M.H., "Densities and viscosities of binary mixtures of $\left\{\right.$ dimethylsulfoxide+aliphatic lower alkanols $\left(\mathrm{C}_{1}-\mathrm{C}_{3}\right)$ \} at temperatures from T=303.15 K to T=323.15 K", J. Chem. Thermodyn., 2007, 39, 675-683.

Calvignac B., Rodier E., Letourneau J.-J., Fages J., "Characterization of melted cocoa butter saturated with supercritical $\mathrm{CO}_{2}$ ", Proceedings of the $2^{\text {nd }}$ International congress on Green Process Engineering, Venice (Italy), 2009a. 
Calvignac B., Vitoux P., Rodier E., Letourneau J.-J., Aymonier C., Fages J., "Development of a falling body viscosimeter for high pressure measurements", Proceedings of the $9^{\text {th }}$ International Symposium on Supercritical Fluids, Arcachon (France), ISBN 978-2-9511591-7-4, 2009b.

Calvignac B., Boutin O., "The impinging jets technology: A contacting device using a SAS process type", Powder Technol., 191, 2009c, 200-205.

Chiu H.-Y., Jung R.-F., Lee M.-J., Lin H.M., "Vapor-liquid equilibrium behaviour of mixtures containing supercritical carbon dioxide near critical region", J. Supercrit. Fluids, 2008, 44, 273-278.

Cocero M.J., Martín A., Mattea F., Varona S., "Encapsulation and coprecipitation processes with supercritical fluids: Fundamentals and applications", J. Supercrit. Fluids, 47, 2009, 546-555.

Elvassore N., Bertucco A., Di Noto V., "On-line monitoring of volume expansion in gas-antisolvent processes by UV-vis spectroscopy", J. Chem. Eng. Data, 2002, $47,223$.

Fages J., Lochard H., Letourneau J.-J., Sauceau M., Rodier E., "Particle generation for pharmaceutical applications using supercritical fluid technology", Powder Technol., 2004, 141, 219-229.

Kapoor B., Bhattacharya M., "Dynamic and extensional properties of starch in aquous dimethylsulfoxide", Carbohydr. Polym., 2000, 42, 323-335.

Kordidowski A., Schrenk A.P., Van Nielen R.M., Peters C.J., "Volume expansions and vapor-liquid equilibrium of binary mixtures of a variety of polar solvents and certain near-critical solvents", J. Supercrit. Fluids, 1995, 8, 205-216.

Majerik V., Charbit G., Badens E., Horváth G., Szokonya L., Bosc N., Teillaud E., "Bioavailability enhancement of an active substance by supercritical antisolvent precipitation", J. Supercrit. Fluids, 40, 2007, 101-110.

Rajasingam R., Lioe L., Pham T., Lucien F.P., "Solubility of carbon dioxide in dimethylsulfoxide and N-methyl-2pyrrolidone at elevated pressure", J. Supercrit. Fluids, 2004, 31, 227-234. 
Rodier E., Lochard H., Sauceau M., Letourneau J.-J., Freiss B, Fages J., "A three step supercritical process to improve the dissolution rate of Eflucimibe", Eur. J.Pharm. Sci., 2005, 26, 184-193.

Span R., Lemmon, E.W., Jacobsen, R.T., Wagner, W., Yokozeki, A., "A Reference Equation of State for the Thermodynamic Properties of Nitrogen for Temperatures from 63.151 to $1000 \mathrm{~K}$ and Pressures to $2200 \mathrm{MPa}$ ", J. Phys. Chem. Ref. Data, 2000, 29, 6, 1361-1433.

Su C-S, Tang M., Chen Y-P, "Recrystallization of pharmaceuticals using the batch supercritical anti-solvent process", Chem. Eng. Process.: Process Intensification, 48, 2009, 92-100.

Vega Gonzalez A., Tufeu R., Subra P., "High-pressure vapor-liquid equilibirum for binary systems carbon dioxide + dimethyl sulfoxide and carbon dioxide + Dichloromethane", J. Chem. Eng. Data, 2002, 47, 492-495.

Vitoux P., Majimel M., Tassaing T., Letourneau J.J., Cansell F., Aymonier C., "Application of polymer swelling by $\mathrm{scCO}_{2}$ to the synthesis of polymer/metal nanocomposites", Solid State Phenom., 2009, 151, 24-29.

Wagner W., Pruss A., "The IAPWS formulation 1995 for the thermodynamic properties of ordinary water substance for general and scientific use", J. Phys. Chem. Ref. Data, 2002, 31, 2, 387-535.

Yeo S.-D., Lim G.-B., Debenedetti P.G., Bernstein H., "Formation of microparticulate protein powders using a supercritical fluid antisolvent", Biotech. Bioeng., 1993, 41, 341. 